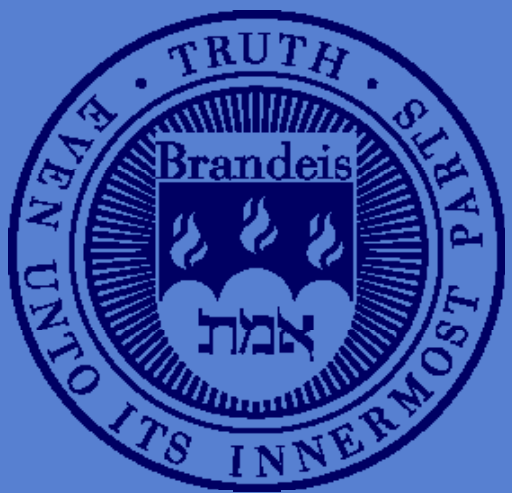

Interest Rates and the Market for New Light Vebicles

George Hall, Economics Department, Brandeis University

Adam Copeland, Federal Reserve Bank of New York

Louis Maccini, Johns Hopkins University

Working Paper Series 


\title{
Interest Rates and the Market for New Light Vehicles*
}

\author{
Adam Copeland \\ Federal Reserve Bank of New York ${ }^{\dagger}$ \\ George Hall \\ Brandeis University ${ }^{\ddagger}$ \\ Louis Maccini \\ Johns Hopkins University ${ }^{\S}$
}

September 18, 2015

\begin{abstract}
We study the impact of interest rates changes on both the demand and supply of new light vehicles in an environment where consumers and manufacturers face their own interest rates. An increase in the consumers' interest rate raises their cost of financing and thus lowers the demand for new vehicles. An increase in the manufacturers' interest rate raises their cost of holding inventories. Both channels have equilibrium effects that are amplified and propagated over time through inventories, which serve as a way to both smooth production and facilitate greater sales at a given price. Through the estimation of a dynamic stochastic market equilibrium model, we find evidence of both channels at work and of the important role played by inventories. A temporary 100 basis-point increase in both interest rates causes vehicle production to fall 12 percent and sales to fall 3.25 percent at an annual rate in the short run.
\end{abstract}

Keywords: interest rates, automobiles, inventories, Bayesian maximum likelihood.

JEL classification numbers: E44, G31.

\footnotetext{
${ }^{*}$ We thank James Kahn, Adrian Pagan, and numerous seminar participants for thoughtful comments. The views expressed do not represent the views of the Federal Reserve Bank of New York or the Federal Reserve system.

${ }^{\dagger}$ Federal Reserve Bank of New York, 33 Liberty Street New York, NY 10045; phone (212) 720-7490; email: adam.copeland@ny.frb.org

${ }^{\ddagger}$ Brandeis University, Department of Economics, 415 South Street, Waltham, MA 02454-9110; phone: (781) 736-2242; email: ghall@brandeis.edu

$\S$ Johns Hopkins University, Department of Economics, 3400 N. Charles Street, Baltimore, MD 21218; phone: (410) 322-9589; email: maccini@jhu.edu
} 


\section{Introduction}

This paper measures the dynamic response of real prices, sales, production, and inventories to changes in real interest rates for a particular durable goods market - new cars and light trucks. This is an important issue because the market for durable goods is a key channel through which monetary policy affects the real economy.

Changes in real interest rates affect both sides of the market for durable goods. For consumers who purchase durable goods on credit, higher real rates increase the cost of borrowing, inducing a decline in demand. Hence, sales and real prices should fall. Depending on the speed with which manufacturers reduce production in response to this shock, inventories may rise or fall in the short run. We refer to the effect of higher real interest rates on consumer purchases of durable goods as the household expenditure channel. For manufacturers of durable goods, higher real interest rates raise the cost of holding inventories, inducing them to economize on inventories by cutting real prices to raise sales and by reducing production. However, if higher inventories facilitate sales by making it easier for consumers to be matched with the precise product they want, the reduction in inventories will dampen sales. Hence, the overall impact of higher real interest rates on manufacturers' sales is ambiguous. We refer to the effect of higher real interest rates on durable goods producers as the firm inventory channel. These countervailing forces suggest that the responses of sales and inventories to changes in interest rates may be nonmonotonic, helping explain why previous research has found little effect of real interest rates on these two variables in durable goods markets.

We analyze how changes in real interest rates affect the U.S. market for new cars and light trucks through the household expenditure and firm inventory channels. New motor vehicles are the quintessential durable good comprising a little over 25 percent of all durable goods expenditures by U.S. households. Furthermore, given the industrial organization of the market for new vehicles, we expect interest rates to affect both sides of the market. On the supply side, the vast majority of automobiles are built to stock, with the typical dealer holding three months of sales in inventory. Because interest rates are an important component of inventory holding costs, theory suggests that firms will reduce inventory levels in response to increases in interest rates. ${ }^{1}$ On the demand side, higher real interest rates raise the total cost of buying a vehicle for many consumers. In addition, the purchase of any durable good has an intertemporal component; the more the consumer discounts the future, the lower the return is to the consumer from buying the good in the present period. Consequently, we expect higher interest rates to dampen consumer demand. Although the automobile market is well suited for assessing the responses of both firms

\footnotetext{
${ }^{1}$ For the sample of dealerships reported in appendix 1 of Baines and Courchane (2013), from 2002 to 2011 these "floorplan interest expenses" averaged $\$ 288,000$ per year per dealership or $\$ 166$ per vehicle sold. The average gross profit per new vehicle sold was roughly $\$ 2,300$, so that these interest costs represent roughly 7 percent of gross profits.
} 
and consumers to interest rate changes, the mechanisms we identify should apply to other durable goods industries as well.

We construct a dynamic model of the market for new automobiles that embeds these two channels. On the demand side, the model consists of a representative household that incurs shopping costs when deciding on which cars to purchase and chooses between overall purchases of new automobiles and other consumption goods to maximize its discounted flow of expected utility. The household faces a stochastic interest rate at which it can borrow and finances new car purchases with income and loans. On the supply side, the model consists of a representative producer of new automobiles. This firm is a monopolistic competitor that maximizes the discounted flow of expected profits. The firm faces a stochastic interest rate and holds inventories to facilitate sales. Specifically, higher available supply - that is, beginning-of-period inventories plus current production - reduces the household's shopping costs. The solution of our model determines the equilibrium real prices, sales, and output of new cars.

There are high-quality data on automobiles, from total sales and output by producers to household expenditures on automobiles. Combining these timeseries with data on interest rates faced by producers and by households, we construct a panel dataset of monthly data from 1972 to 2011. With these data, we estimate our model by means of a Bayesian maximum likelihood procedure. As evidence of goodness of fit, we demonstrate that our estimated model successfully replicates results from recursive vector autoregressions, which indicate that an increase in interest rates paid by households and firms generates a modest but significant reduction in both the ratio of output to sales and the ratio of available supply to sales.

We find that changes in the interest rates faced by firms and consumers have a significant impact on the automobile market at the monthly frequency. A 100 basis-point increase in both interest rates causes automobile production to fall nearly 12 percent and sales to fall 3.25 percent at an annual rate. Since production falls by more than sales, available supply relative to sales also decreases. If we assume that 17 million new cars and light trucks are produced and sold in the United States each year, this response translates into about 170,000 fewer cars produced and 46,000 fewer cars sold in the first two months after the shock. The growth rate of sales remains below its steady state for about six months; for many months thereafter, sales growth slightly exceeds its steady-state rate and only slowly drops back to the steady state. Our theory implies that firm-side and consumer-side responses reinforce each other in the equilibrium and that inventories play a key role in amplifying the impact on sales. Nevertheless, since both output and sales fall, the impact of higher interest rates on the ratio of available supply to sales is small.

We build on a substantial literature on the market for automobiles. The vast majority of studies focus on either the consumer/demand side or the firm/supply side. On the demand side, much of the work focuses on the role of credit constraints in the auto loan market. Examples are Chah, Ramey, and Starr (1995); Alessie, Devereux, and Weber (1997); Ludvigson (1998); and 
Attanasio, Goldberg, and Kyriazidou (2008). ${ }^{2}$ This literature, however, does not explicitly model the supply side of the market. We certainly agree that credit constraints on both consumers and firms play an important role in the auto market beyond simply the posted interest rate. ${ }^{3}$ However, our model suggests that interest-rate changes will affect sales through both the demand side and the supply side. Hence, a market analysis is needed to understand the impact that interest rates, credit market conditions, and monetary policy have on sales in the market for automobiles.

On the supply side, a number of studies of automobile firms have explored the relationship between inventories and production. See, for example, Blanchard (1983); Kahn (1992); Kashyap and Wilcox (1993); Ramey and Vine (2006); and Copeland and Hall (2011). However, this literature takes quantity demanded as given. Furthermore, this literature assumes that real interest rates are constant and thus does not address the effects of interest rates on automobile production and inventories. This gap highlights a broader puzzle in empirical research on inventories: over a long period of time, very few studies have uncovered a significant relationship between real interest rates and inventories. ${ }^{4}$ This is an important issue for several reasons. One is that, in theory, monetary policy changes short-term real interest rates and thereby influences inventory investment. The other is that the financial press is filled with ad hoc statements of how interest rates affect inventories both by influencing the cost to firms of holding inventories and by affecting sales, which, in turn, cause changes in inventory positions. ${ }^{5}$ The lack of empirical evidence on the mechanism by which real interest rates affect inventories is therefore troubling.

Since our analysis attempts to look at both the consumer-side and the firm-side decisions simultaneously, this paper builds most closely on the work of Blanchard and Melino (1986), who also develop a model of the market for automobiles. ${ }^{6}$ There are two primary innovations in our model relative to theirs. First, we allow real interest rates to be variable and stochastic. We are thus able to explore the effects of real interest rates on sales, production, prices, and inventories in the market, which they cannot do. We also distinguish between the real interest rates faced by households and those faced by firms. Second, Blanchard and Melino model the automobile industry as a perfectly competitive one. In contrast, we assume that producers of automobiles

\footnotetext{
${ }^{2}$ Additional influential papers on the demand for automobiles include Adda and Cooper (2006), Copeland (2014), Eberly (1994), and Schiraldi (2011).

${ }^{3}$ In the recent financial crisis, despite a Fed Funds rate near zero, many consumers were unable to obtain new car loans, which contributed to a plummet in auto sales and pushed G.M. and Chrysler into bankruptcy.

${ }^{4}$ See Blinder and Maccini (1991) and Ramey and West (1999) for surveys of the literature. Maccini, Moore, and Schaller $(2004,2015)$ are exceptions in that they provide evidence that inventories respond to long-run movements or regime shifts in real interest rates. However, they treat sales as given and therefore do not take up the effect of real interest rates on inventories operating through sales.

${ }^{5}$ A search of industry publications such as Automotive News and WardsAuto.com illustrates that dealers are keenly aware of these expenses in articles with headlines such as "Interest rate spike would trim inventories: The industry could live with a modest increase." See LaReau (2013).

${ }^{6}$ In the literature on industrial organization, there are papers that model both sides of a durable goods market, such as Nair (2007), Esteban and Shum (2007), Goettler and Gordon (2009), Copeland, Dunn, and Hall (2011), and Chen, Esteban, and Shum (2013). Relative to our paper, this literature focuses on different questions and employs different methods.
} 
are monopolistic competitors, and we develop a shopping-cost model for the household to decide on automobile purchases, which yields a demand function for new automobiles that firms face. As in Bils and Kahn (2000), the demand function implies that inventories play a productive role in stimulating demand.

In the remainder of this paper, we present our model of the market for new automobiles, discuss the construction of our dataset, present estimates of the model parameters, and illustrate the dynamic responses to interest rate shocks of key variables in our model.

\section{Model of the Market for New Automobiles}

\subsection{Model of the household}

The representative household undertakes a two-stage optimization process. In the first stage, the household minimizes the shopping costs of purchasing automobiles. Given this outcome, in the second stage the household maximizes utility.

In the first stage, the household minimizes the costs of purchasing automobiles. The costs consist of both purchase costs and shopping costs. Define $P_{j t}$ as the real price of a new automobile of type $j$ and $S_{j t}$ as the quantity of new automobiles of type $j$ purchased at time $t .{ }^{7}$ Then $P_{j t} S_{j t}$ is the real cost of purchasing new automobiles of type $j$ at time $t$.

Define $\phi\left(\frac{A_{j t}}{A_{t}}\right) S_{j t}$ as the total real shopping cost of purchasing new automobiles of type $j$, where $\phi\left(\frac{A_{j t}}{A_{t}}\right)$ is the real per unit shopping cost of purchasing new automobiles of type $j$, $A_{j t}=N_{j t-1}+Y_{j t}$ is the supply of new automobiles available for sale in period $t$ by producer of type $j, N_{j t-1}$ is the stock of inventories of new autos of type $j$ held by the producer of type $j$ autos at the end of period $t-1, Y_{j t}$ is the current production of new automobiles by producer of type $j, A_{t}=N_{t-1}+Y_{t}$ is the supply of new automobiles available for sale in the industry as a whole, $N_{t-1}$ is the stock of inventories of all new autos in the industry, $Y_{t}$ is current production in the industry as a whole, and where we assume that $\phi^{\prime}<0$. The basic idea is that the shopping cost to the household declines the higher is the supply of new cars that firm $j$ has available for sale relative to the supply of new automobiles available for sale in the industry as a whole. The higher the supply of inventories that firm $j$ has available for sale, the higher the probability is that there will be a match between the household's decision to buy an automobile of type $j$ and firm $j .^{8}$ Then, $\phi\left(\frac{A_{j t}}{A_{t}}\right) P_{j t} S_{j t}$ is the total real shopping cost of purchasing new automobiles of type $j$ valued at $P_{j t}$. Finally, the total real cost of purchasing new automobiles of type $j$ is the sum of the purchase costs plus the shopping costs, or

\footnotetext{
${ }^{7}$ Specifically, $P_{j t}$ is the nominal price of new automobiles of type $j$ divided by the price of consumption, excluding car services.

${ }^{8}$ See Jung and Yun (2007) for a similar specification of shopping costs that is used to derive a demand function faced by a monopolistic firm.
} 


$$
P_{j t} S_{j t}+\phi\left(\frac{A_{j t}}{A_{t}}\right) P_{j t} S_{j t}=\left[1+\phi\left(\frac{A_{j t}}{A_{t}}\right)\right] P_{j t} S_{j t}
$$

Now, in the first stage, the representative household chooses $S_{j t}$ to minimize

$$
\int_{0}^{1}\left[1+\phi\left(\frac{A_{j t}}{A_{t}}\right)\right] P_{j t} S_{j t} d j
$$

subject to

$$
S_{t}=\left[\int_{0}^{1} S_{j t}^{\frac{\varepsilon-1}{\varepsilon}} d j\right]^{\frac{\varepsilon}{\varepsilon-1}}
$$

where $\epsilon>1$. Assume that shopping costs take the form

$$
\phi\left(\frac{A_{j t}}{A_{t}}\right)=\left(\frac{A_{j t}}{A_{t}}\right)^{\nu}-1
$$

with $\nu<0$. Then, in appendix A we show that the solution to this problem yields a demand function for new automobiles of type $j$ of the form

$$
S_{j t}=\left(\frac{P_{j t}}{P_{t}}\right)^{-\varepsilon}\left(\frac{A_{j t}}{A_{t}}\right)^{\theta} S_{t}
$$

where $S_{t}$ is the aggregate purchases of new automobiles, $P_{t}$ is the average real price of new automobiles, and $\theta=-\epsilon \nu>0$. This is the demand function faced by the firm that produces new automobiles of type $j$. We refer to $\epsilon$ as the own-price elasticity and to $\theta$ as the available-supply elasticity of the demand for new automobiles.

In the second stage, the representative household is assumed to choose $C_{t}, X_{t}, S_{t}, B_{t}$, and $D_{t}$ to maximize

$$
E_{o} \sum_{t=0}^{\infty} \zeta^{t} U\left(C_{t}, X_{t}\right)
$$

subject to

$$
\begin{gathered}
C_{t}+(1-\bar{\xi}) P_{t} S_{t}+r_{1 t} B_{t-1}+\mu B_{t-1}=I_{t} \\
X_{t}=(1-\delta) X_{t-1}+S_{t} \quad 0<\delta<1 \\
B_{t}=(1-\mu) B_{t-1}+D_{t} \\
D_{t}=\bar{\xi} P_{t} S_{t} \quad 0<\mu<1 \\
\end{gathered}
$$


where $C_{t}$ denotes consumption, excluding car services, $X_{t}$ is the stock of existing cars, $S_{t}$ is purchases of new cars, $I_{t}$ denotes real labor income, $B_{t}$ represents the stock of car loans, $D_{t}$ is new loans incurred to purchase automobiles, $P_{t}$ is the average real price of new cars, $r_{1 t}$ is the real interest rate on new car loans, $\bar{\xi}$ is the fraction of a new car purchase financed by a new loan, $\delta$ is the rate that cars depreciate, and $\mu$ is the fraction of existing loans that needs to be paid back every period.

Following a number of papers in the literature, for example, Blanchard and Melino (1986) and Alessie, Devereux, and Weber (1997), we treat the stock of cars as a continuous variable and the household as a representative one whose purchases add to the stock of cars. The household derives utility from the services provided by the automobiles it possesses, which is proportional to the stock of automobiles where the proportionality factor is normalized to unity, and from consumption of goods other than automobiles, which we will refer to simply as "consumption." As equation (8) indicates, purchases of new automobiles, $S_{t}$, add to the stock, which in turn also depreciates at rate $\delta$. Purchases of new automobiles are financed in part with income, $(1-\bar{\xi}) P_{t} S_{t}$, and in part with new loans, $D_{t}=\bar{\xi} P_{t} S_{t}$. The budget constraint, equation (7), incorporates the payment of interest on loans, $r_{1 t} B_{t-1}$, and the amount of the stock of loans that is paid back each period, $\mu B_{t-1}$, where the fraction that is paid back is assumed to be constant.

Assume that the utility function is

$$
\begin{aligned}
U\left(C_{t}, X_{t}\right) & =\pi_{1} \ln C_{t}+\pi_{2} \ln X_{t} \\
\pi_{1} & >0 \quad \pi_{2}>0
\end{aligned}
$$

and use equation (10) to eliminate $D_{t}$. The first-order conditions are then

$$
\begin{gathered}
\frac{\pi_{1}}{C_{t}}=\lambda_{1 t}^{h} \\
(1-\delta) \zeta E_{t} \lambda_{2 t+1}^{h}+\frac{\pi_{2}}{X_{t}}=\lambda_{2 t}^{h} \\
\lambda_{2 t}^{h}-(1-\bar{\xi}) P_{t} \lambda_{1 t}^{h}+\bar{\xi} P_{t} \lambda_{3 t}^{h}=0 \\
(1-\mu) \zeta E_{t} \lambda_{3 t+1}^{h}-\zeta E_{t}\left(r_{1 t+1}+\mu\right) \lambda_{1 t+1}^{h}=\lambda_{3 t}^{h}
\end{gathered}
$$

together with equations (7), (8), and (9). The endogenous variables are then $C_{t}, X_{t}, S_{t}, B_{t}$ and the multipliers are $\lambda_{1 t}^{h}, \lambda_{2 t}^{h}$ and $\lambda_{3 t}^{h}$.

The household expenditure channel is embodied in these first-order conditions. The three mul- 
tipliers represent the marginal utility of consumption $\left(\lambda_{1 t}^{h}\right)$, the marginal utility of the automobile stock $\left(\lambda_{2 t}^{h}\right)$, and the marginal disutility from consumer automobile debt $\left(\lambda_{3 t}^{h}\right)$. The first-order condition, equation (14), states that the cost to the household from purchasing more autos is the sum of $(1-\bar{\xi}) P_{t}$ times the cost of the forgone current period consumption and $\bar{\xi} P_{t}$ times the disutility of more debt. Since the household choice between $C_{t}$ and $S_{t}$ depends on future interest rates, an increase in the current interest rate, $r_{1 t}$, acts just like a drop in income, reducing the demand for both goods. An increase in next period's interest rate $r_{1 t+1}$ increases future disutility of auto debt, thus increasing the price of purchasing a new automobile relative to nonauto consumption.

\subsection{Model of the firm}

We consider a representative firm, firm $j$, that produces and sells a single durable good, namely, a type of new automobile, type $j$. The firm is an integrated dealer-producer. ${ }^{9}$ The firm is a monopolistic competitor that faces a stochastic downward-sloping demand curve for its product and a variable and stochastic interest rate at which it discounts future profits. Each period, the representative firm, firm $j$, maximizes:

$$
P V_{j}=E_{o} \sum_{t=0}^{\infty}\left[\Pi_{s=0}^{t} \beta_{s}\right] \Phi_{j t}
$$

where

$$
\begin{gathered}
\beta_{s}=\frac{1}{1+r_{2 s}} \\
\Phi_{j t}=\frac{P_{j t}}{P_{t}} S_{j t}-\frac{W_{t}}{P_{t}} L_{j t}-K_{j t}
\end{gathered}
$$

subject to:

$$
\begin{gathered}
S_{j t}=\left(\frac{P_{j t}}{P_{t}}\right)^{-\varepsilon}\left(\frac{A_{j t}}{A_{t}}\right)^{\theta} S_{t} \quad \epsilon>1 \quad \theta>0 \\
K_{j t}=\kappa_{o}\left(\frac{A_{j t}}{S_{j t}}\right)^{\kappa_{1}} N_{j t-1} \quad \kappa_{1}>0 \\
A_{j t}=N_{j t-1}+Y_{j t} \\
A_{j t}=A_{j t-1}-S_{j t-1}+Y_{j t}
\end{gathered}
$$

\footnotetext{
${ }^{9}$ We integrate the dealership into the automaker and consider a unified pricing decision. See Blanchard (1983, page 370) for the argument for treating the manufacturer and the dealer as a single entity.
} 


$$
Y_{j t}=\Gamma_{j t} L_{j t}^{\alpha} \quad 0<\alpha<1
$$

where $P_{j t}$ is the real price firm $j$ sets for an automobile of type $j, S_{j t}$ is sales of automobiles of type $j$ by firm $j, L_{j t}$ is labor services, $N_{j t}$ is the stock of inventories of firm $j$ of finished automobiles at the end of the period, $A_{j t}$ is the stock of goods available for sale during period $\mathrm{t}, Y_{j t}$ is the output of automobiles of type $j, \Gamma_{j t}$ is labor productivity, $r_{2 t}$ is the real interest rate faced by the firm, $K_{j t}$ is inventory storage costs, $S_{t}$, is industry sales, $N_{t}$ is the industry stock of inventories of finished automobiles at the end of the period, $P_{t}$ is the real industry price level, and $W_{t}$ is the real wage rate.

Observe that equation (19) is the demand function for new automobiles of type $j$ that emerged from the shopping-cost model of the household. The demand for new cars from the representative household thus serves as the demand function faced by firm $j$, which is the firm that produces automobiles of type $j$. This connects the model of the household to the model of the firm.

Using the definition of $A_{j t}$ inventory storage costs, equation (20), can be written as

$$
K_{j t}=\kappa_{o}\left(\frac{A_{j t}}{S_{j t}}\right)^{\kappa_{1}} N_{j t-1}=\kappa_{o}\left(\frac{N_{j t-1}+Y_{j t}}{S_{j t}}\right)^{\kappa_{1}} N_{j t-1}
$$

Current-period storage costs are thus assumed to rise with the stock of automobile inventories carried over from the previous period and with current production and to fall with current sales. Now, use equation (19) to eliminate price as an explicit choice variable and rewrite equation (21) to get $N_{j t-1}=A_{j t}-Y_{j t}$; then net revenues, equation (18), can be written as

$$
\Phi_{j t}=\left(\frac{S_{j t}}{S_{t}}\right)^{1-\frac{1}{\varepsilon}}\left(\frac{A_{j t}}{A_{t}}\right)^{\frac{\theta}{\varepsilon}} S_{t}-\frac{W_{t}}{P_{t}} L_{j t}-\kappa_{o}\left(\frac{A_{j t}}{S_{j t}}\right)^{\kappa_{1}}\left(A_{j t .}-Y_{j t}\right) .
$$

The firm then chooses $S_{j t}, Y_{j t}, A_{j t}$, and $L_{j t}$ to maximize equation (16) subject to equations (22) and (23) and where net revenue is now defined in equation (24) and the discount factor is again given by equation (17). The first-order conditions are

$$
\begin{gathered}
\left(\frac{\varepsilon-1}{\varepsilon}\right)\left(\frac{S_{j t}}{S_{t}}\right)^{-\frac{1}{\varepsilon}}\left(\frac{A_{j t}}{A_{t}}\right)^{\frac{\theta}{\varepsilon}}+\kappa_{o} \kappa_{1}\left(\frac{A_{j t}}{S_{j t}}\right)^{\kappa_{1}}\left(\frac{A_{j t .}-Y_{j t}}{S_{j t}}\right)=E_{t} \beta_{t+1} \lambda_{1 t+1}^{f} \\
\kappa_{o}\left(\frac{A_{j t}}{S_{j t}}\right)^{\kappa_{1}}+\lambda_{1 t}^{f}=\lambda_{2 t}^{f} \\
E_{t} \beta_{t+1} \lambda_{1 t+1}^{f}+\left(\frac{\theta}{\varepsilon}\right)\left(\frac{S_{j t}}{S_{t}}\right)^{1-\frac{1}{\varepsilon}}\left(\frac{A_{j t}}{A_{t}}\right)^{\frac{\theta}{\varepsilon}-1}\left(\frac{S_{t}}{A_{t}}\right)
\end{gathered}
$$




$$
\begin{gathered}
-\kappa_{o}\left(\frac{A_{j t}}{S_{j t}}\right)^{\kappa_{1}}\left[\kappa_{1}\left(\frac{A_{j t}}{S_{j t}}\right)^{-1}\left(\frac{A_{j t}-Y_{j t}}{S_{j t}}\right)+1\right]=\lambda_{1 t}^{f} \\
\alpha \lambda_{2 t}^{f} \Gamma_{j t} L_{j t}^{\alpha-1}=\frac{W_{t}}{P_{t}}
\end{gathered}
$$

where $\beta_{t+1}=\frac{1}{1+r_{2 t+1}}$, and $\lambda_{1 t}^{f}$ and $\lambda_{2 t}^{f}$ are the multipliers associated with the available-supplyaccumulation process and the production function, equations (22) and (23), respectively. From equation (26), we see that the multiplier $\lambda_{2 t}^{f}$ measures the negative of the marginal cost to the firm of producing an additional automobile. Equation (28) states that the firm will set the marginal cost of producing an additional vehicle to the marginal value of an additional unit of inventory.

These optimality conditions summarize the endogenous dynamics of the supply side of the model. The multiplier $\lambda_{1 t}^{f}$ measures the marginal value to the firm of an additional unit of inventory. Thus, equation (27) equates the costs and benefits to the firm of selling the marginal vehicle. The right-hand side of the equation is the marginal revenue from selling one more vehicle this period. The three terms on the left-hand side of the equation are: (1) the marginal revenue from selling the vehicle next period; (2) the marginal benefit to the firm of having an additional unit of inventory (the value from the increase in demand for its vehicles) next period; and (3) the marginal storage cost of holding an additional vehicle one more period The higher is $r_{2, t+1}$, the smaller the benefit is to holding a vehicle in inventory one more period. This equation captures the firm inventory channel. A firm that faces an unexpected high interest rate next period will wish to hold fewer vehicles in inventory. Thus, higher interest rates should lead to lower prices and more sales in the short run. But a reduction in available supply will feed into the household's problem, reducing consumer demand.

\subsection{Market equilibrium}

In market equilibrium, we assume that $S_{j t}=S_{t}, A_{j t}=A_{t}, L_{j t}=L_{t}, Y_{j t}=Y_{t}$, and $\Gamma_{j t}=\Gamma_{t}$. Then, the optimality conditions and constraints for the firm become

$$
\begin{gathered}
\left(\frac{\varepsilon-1}{\varepsilon}\right)+\kappa_{o} \kappa_{1}\left(\frac{A_{t}}{S_{t}}\right)^{\kappa_{1}}\left(\frac{A_{t .}-Y_{t}}{S_{t}}\right)=E_{t} \beta_{t+1} \lambda_{1 t+1}^{f} \\
\kappa_{o}\left(\frac{A_{t}}{S_{t}}\right)^{\kappa_{1}}+\lambda_{1 t}^{f}=\lambda_{2 t}^{f} \\
E_{t} \beta_{t+1} \lambda_{1 t+1}^{f}+\left(\frac{\theta}{\varepsilon}\right)\left(\frac{A_{t}}{S_{t}}\right)^{-1}-\kappa_{o}\left(\frac{A_{t}}{S_{t}}\right)^{\kappa_{1}}\left[\kappa_{1}\left(\frac{A_{t}}{S_{t}}\right)^{-1}\left(\frac{A_{t}-Y_{t}}{S_{t}}\right)+1\right]=\lambda_{1 t}^{f} \\
\alpha \lambda_{2 t} \Gamma_{t} L_{t}^{\alpha-1}=\frac{W_{t}}{P_{t}}
\end{gathered}
$$




$$
\begin{gathered}
A_{t}=A_{t-1}-S_{t-1}+Y_{t} \\
Y_{t}=\Gamma_{t} L_{t}^{\alpha}
\end{gathered}
$$

where $\beta_{t+1}=\frac{1}{1+r_{2 t+1}}$. For the household in market equilibrium, the optimality conditions and the constraints are

$$
\begin{gathered}
\frac{\pi_{1}}{C_{t}}=\lambda_{1 t}^{h} \\
(1-\delta) \zeta E_{t} \lambda_{2 t+1}^{h}+\frac{\pi_{2}}{X_{t}}=\lambda_{2 t}^{h} \\
\lambda_{2 t}^{h}-(1-\bar{\xi}) P_{t} \lambda_{1 t}^{h}+\bar{\xi} P_{t} \lambda_{3 t}^{h}=0 \\
(1-\mu) \zeta E_{t} \lambda_{3 t+1}^{h}-\zeta E_{t}\left(r_{1 t+1}+\mu\right) \lambda_{1 t+1}^{h}=\lambda_{3 t}^{h} \\
C_{t}+(1-\bar{\xi}) P_{t} S_{t}+\left(r_{1 t}+\mu\right) B_{t-1}=I_{t} \\
X_{t}=(1-\delta) X_{t-1}+S_{t} \\
B_{t}=(1-\mu) B_{t-1}+\bar{\xi} P_{t} S_{t} .
\end{gathered}
$$

The market equilibrium model thus contains thirteen equations in thirteen endogenous variables: $S_{t}, Y_{t}, A_{t}, L_{t}, C_{t}, P_{t}, X_{t}, B_{t}, \lambda_{1 t}^{h}, \lambda_{2 t}^{h}, \lambda_{3 t}^{h}, \lambda_{1 t}^{f}$, and $\lambda_{2 t}^{f}$.

\subsection{Ratios and growth rates}

Our estimation approach relies on the data being stationary. Although unit sales of light vehicles and the firms' and households' interest rates are stationary, there are trends in real prices, real wages, and real disposable income. Consequently, we reformulate the model so that the relevant variables are in ratio form. These ratios are stationary and thus guard against any statistical problems with nonstationary timeseries. ${ }^{10}$ Define the following ratios and growth rates:

\footnotetext{
${ }^{10}$ An example of a model with an inventory-holding firm that is expressed in ratio form is Maccini and Pagan (2013).
} 


$$
\begin{gathered}
R_{t}^{C I}=\frac{C_{t}}{I_{t}} \quad R_{t}^{P S I}=\frac{P_{t} S_{t}}{I_{t}} \quad R_{t}^{P X I}=\frac{P_{t} X_{t}}{I_{t}} \quad R_{t}^{B I}=\frac{B_{t}}{I_{t}} \\
R_{t}^{A S}=\frac{A_{t}}{S_{t}} \quad R_{t}^{Y S}=\frac{Y_{t}}{S_{t}} \quad L S_{t}=\frac{W_{t} L_{t}}{P_{t} Y_{t}} \\
I_{t}=\left(1+i_{t}\right) I_{t-1} \quad P_{t}=\left(1+p_{t}\right) P_{t-1} \quad S_{t}=\left(1+s_{t}\right) S_{t-1} \quad Y_{t}=\left(1+y_{t}\right) Y_{t-1} \\
L_{t}=\left(1+l_{t}\right) L_{t-1} \quad \Gamma_{t}=\left(1+\gamma_{t}\right) \Gamma_{t-1} \quad W_{t}=\left(1+w_{t}\right) W_{t-1}
\end{gathered}
$$

where $i_{t}$ is the growth rate of real income, $p_{t}$ is the growth rate of the real price of automobiles, $s_{t}$ is the growth rate of real sales, $y_{t}$ is the growth rate of output, $l_{t}$ is the growth rate of labor, $\gamma_{t}$ is the growth rate of labor productivity, and $w_{t}$ is the growth rate of real wages.

The definition of ratios generates three additional equations that relate ratios to growth rates. In particular, observe that the ratios, $R_{t}^{P S I}, R_{t}^{Y S}$, and $L S_{t}$ can be written as

$$
\begin{gathered}
R_{t}^{P S I}=\frac{P_{t} S_{t}}{I_{t}}=\frac{\left(1+p_{t}\right) P_{t-1}\left(1+s_{t}\right) S_{t-1}}{\left(1+i_{t}\right) I_{t-1}}=\frac{\left(1+p_{t}\right)\left(1+s_{t}\right)}{\left(1+i_{t}\right)} R_{t-1}^{P S I} \\
R_{t}^{Y S}=\frac{Y_{t}}{S_{t}}=\frac{\left(1+y_{t}\right) Y_{t-1}}{\left(1+s_{t}\right) S_{t-1}}=\frac{\left(1+y_{t}\right)}{\left(1+s_{t}\right)} R_{t-1}^{Y S} \\
L S_{t}=\frac{W_{t} L_{t}}{P_{t} Y_{t}}=\frac{\left(1+\omega_{t}\right)\left(1+l_{t}\right) W_{t-1} L_{t-1}}{\left(1+p_{t}\right)\left(1+y_{t}\right) P_{t-1} Y_{t-1}}=\frac{\left(1+\omega_{t}\right)\left(1+l_{t}\right)}{\left(1+p_{t}\right)\left(1+y_{t}\right)} L S_{t-1} .
\end{gathered}
$$

In appendix B, we show that, using the ratios and growth rates and eliminating labor input, the model reduces to a system of fifteen equations and fifteen endogenous variables.

\subsection{Exogenous variables}

We assume that each interest rate, $r_{i t}$, is the sum of its mean, a common factor, $f_{t}$, and an idiosyncratic factor, $x_{i t}$. All three latent factors are assumed to be autoregressive:

$$
\begin{gathered}
r_{1 t}=\bar{r}_{1}+\phi f_{t}+x_{1 t} \\
r_{2 t}=\bar{r}_{2}+\phi f_{t}+x_{2 t} \\
f_{t}=\rho_{f} f_{t-1}+\eta_{t}^{f} \\
x_{1 t}=\rho_{x_{1}} x_{1 t-1}+\eta_{t}^{x_{1}}
\end{gathered}
$$




$$
x_{2 t}=\rho_{x_{2}} x_{2 t-1}+\eta_{t}^{x_{2}} .
$$

We allow the growth rates in labor productivity, wages, and income to depend on their own one-period lag as well as a stochastic disturbance:

$$
\begin{aligned}
\gamma_{t} & =\bar{\gamma}\left(1-\rho_{\gamma}\right)+\rho_{\gamma} \gamma_{t-1}+\eta_{t}^{\gamma} \\
w_{t} & =\bar{w}\left(1-\rho_{w}\right)+\rho_{w} w_{t-1}+\eta_{t}^{w} \\
i_{t} & =\bar{\imath}\left(1-\rho_{i}\right)+\rho_{i} i_{t-1}+\eta_{t}^{i} .
\end{aligned}
$$

There are six mutually uncorrelated economic shocks in the model: $\eta^{\Gamma}, \eta^{x_{1}}, \eta^{x_{2}}, \eta^{f}, \eta^{w}$, and $\eta_{t}^{i}$. All six shocks are normally distributed with a mean of zero and constant variance.

\section{Data}

The data in this paper are drawn from a number of sources, although the majority come from the Bureau of Economic Analysis (BEA) and Ward's Automotive Yearbook (various years). To estimate the model, we need data on light motor vehicles describing the growth rates of sales, production, and prices. We also need information on household income, wages, and interest rates faced by households and by automakers. Although most of the data extend farther back in time, our sample starts in February 1972 because of the availability of data on interest rates faced by households and ends in December 2011.

\subsection{Interest rates}

We construct two interest-rate measures, of which one is the rate faced by automakers and the other is that faced by households. For both, we define the real interest as the difference between the nominal interest rate and inflation expectations. We assume the rate faced by automakers is the BAA-bond yield, the interest rate earned on investment-grade bonds. ${ }^{11}$ For households, we take the interest rate reported on 48 -month new car loans issued by commercial banks. ${ }^{12}$ We construct a measure of inflation expectations using a regression approach. Inflation is calculated as the year-over-year change in the personal consumption expenditure price index at the monthly frequency. We then estimate a regression where inflation is the dependent variable and the

\footnotetext{
${ }^{11}$ We used Moody's seasoned BAA-corporate bond yield published by the Board of Governors in its H.14 Selected Interest Rates table.

${ }^{12}$ These data are published by the Federal Reserve Board in its G.19 Consumer Credit table and start in February 1972 .
} 


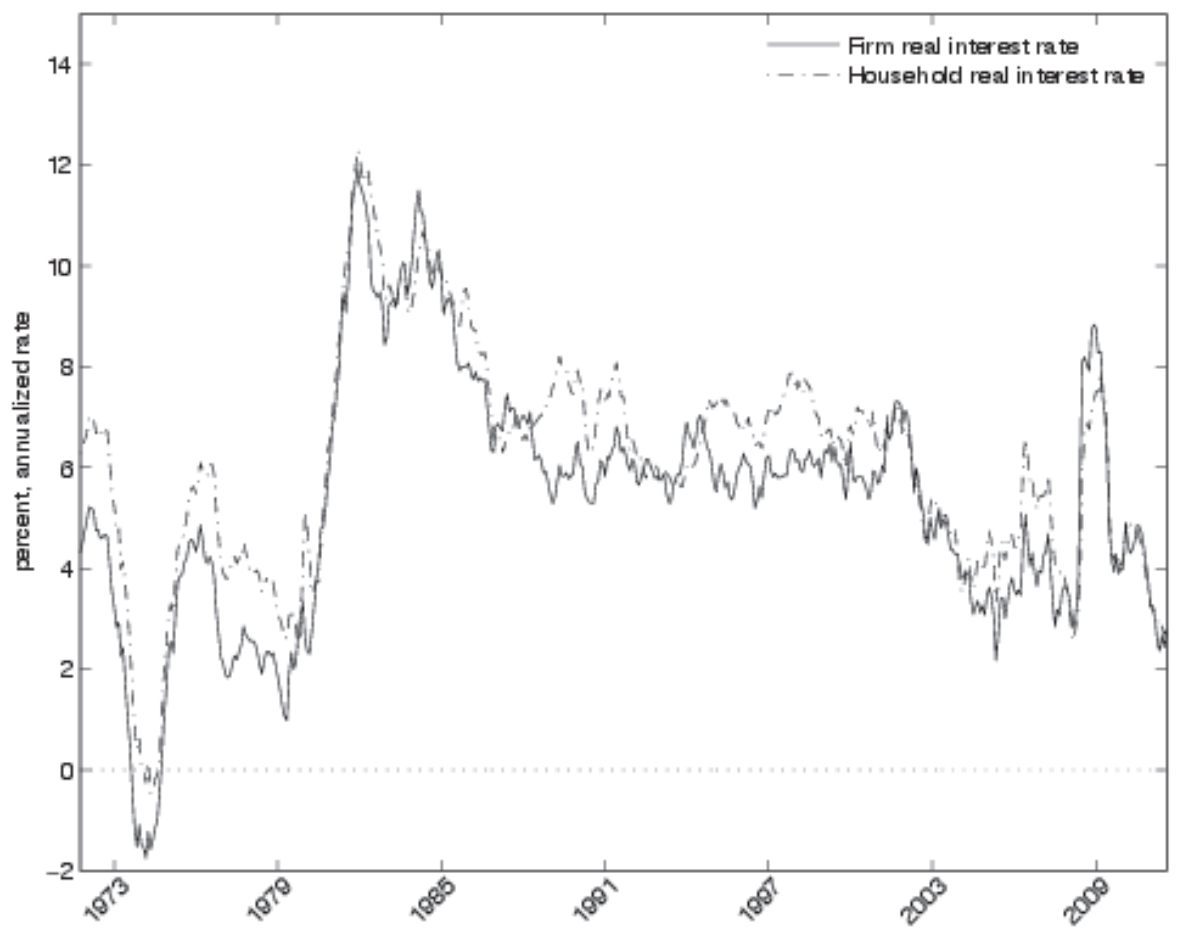

Figure 1: Evolution of Interest Rates over the Sample Period, 1972-2011

independent variables are last month's inflation, contemporaneous values of nominal personal consumption expenditures, industrial production, and the triple-A bond yield. ${ }^{13}$ We estimate inflation expectations in period $t$ using the regression coefficients estimated on data up until and including $t-1$.

Using these ingredients, we construct our two measures of real interest rates, which are plotted in figure 1. Interestingly, the interest rate faced by households is not always above the rate faced by automakers. Indeed, from the late 1990s onward, households could sometimes finance the purchase of their vehicles at rates equal to or below those faced by automakers. This is likely due in part to the competition banks face from automakers' financing entities that offer consumers extremely low financing packages to stimulate sales. ${ }^{14}$

\footnotetext{
${ }^{13}$ Both personal consumption expenditures and the personal consumption expenditures price index are published by the BEA. The industrial production index and Moody's AAA corporate bond yield are published by the Board of Governors in its G.17 Industrial Production and Capacity Utilization and H.15 Selected Interest Rates table, respectively.

${ }^{14}$ Leading up to the 2008-09 financial crisis, for example, U.S. manufacturers advertised their financing incentives under the "zero percent financing" slogan.
} 


\subsection{Sales, production, inventories, and price}

We collect data on units sold, produced, and inventoried separately for automobiles and light trucks. For automobiles, the BEA publishes a comprehensive set of monthly statistics tracking units produced and sold in the United States. A large number of motor vehicles are assembled in Canada and Mexico but sold in the United States. Therefore we follow the BEA nomenclature and define a "domestic" vehicle as one produced in the United States, Canada, or Mexico but intended for the U.S. market. ${ }^{15}$ Our sales data also reflect this domestic label. We then infer domestic inventories from the sales and production flows.

The BEA data for light trucks are less comprehensive and sometimes also have a shorter history. As detailed in appendix C, we use Ward's Automotive data to extrapolate these data back to 1972. We then sum the automotive and light truck sales, output, and inventories data because our model does not distinguish between these two types of passenger vehicles.

We define average price to be equal to the total expenditures on vehicles divided by vehicles sold. The BEA publishes this figure for domestic automobiles, but, once again, some work is needed to construct average prices for light trucks (see appendix $\mathrm{C}$ for details). Guided by the model, we deflate both automobile and light truck nominal prices by a nondurables consumer price index. ${ }^{16}$ The resulting series is now a relative price, measuring how the price of a vehicle compares to the typical nondurable consumption bundle over time. ${ }^{17}$ Finally, we take the salesweighted average of real prices for automobiles and light trucks to arrive at the average real price for light motor vehicles.

Because our model explains monthly growth rates, we compute the percent change in sales, output, and real price. In looking at these data, we see the well-known stylized facts that the growth rates of sales and output have a high correlation of 0.64 and are quite volatile over our sample period, with sales being less volatile than output (e.g., see Bresnahan and Ramey (1994)). This volatility is illustrated in figure 2. Comparing sales and output growth with real price growth

\footnotetext{
${ }^{15} \mathrm{~A}$ small number of cars and trucks are assembled in the United States and exported. These vehicles are not considered part of domestic production. Blanchard and Melino (1986) also note that automobile production "is rather arbitrarily distributed" across countries. Rather than determine which vehicles built in Canada and Mexico are sent to the U.S. market, they look at North America as a whole.

${ }^{16}$ We use the seasonally adjusted U.S. city average nondurables price index published by the Bureau of Labor Statistics.

${ }^{17}$ In contrast to our approach, Blanchard and Melino (1986) use the consumer price index (CPI) component for new cars divided by the personal consumption expenditures (PCE) deflator to construct their relative price measure. We do not use this relative price measure, however, because the CPI component for new cars is a qualityadjusted price, while our measures of units sold, produced, and inventoried are not quality adjusted. Because there is substantial quality adjustment for new cars and light trucks, there is a large mismatch between the qualityadjusted prices and regular units sold. Using the Frisch product rule, we can construct a quality-adjusted quantity index for new automobile sales. By the end of the 1967-2008 period, quality-adjusted units sales are twice the level of regular unit sales. Finally, the use of quality-adjusted prices is not appropriate for our model. Automakers spend significant resources investing in quality-improving technology. We take these quality improvements as given, and consider the firm's pricing and production decisions. As such, vehicle prices in our model should reflect the increase in quality over time.
} 
in figure 2 highlights the finding that the percentage changes in real prices are substantially smaller than sales and output. Over the sample period, real prices are somewhat positively correlated with sales and output, with correlation coefficients of 0.22 and 0.25 , respectively.

Given this paper's focus on interest rates, we consider how prices, sales, and output fluctuate with interest rates in the data. Over our sample period, we find that the percentage changes in firms' real interest rate and in real prices are positively correlated (the correlation coefficient is 0.52 ), a pattern illustrated in figure 3. Given the high correlation between firms' and the households' interest rates, it is not a surprise to find the same positive correlation between the percentage changes in households' real interest rate and in real prices. Finally we also find that the percentage changes in firms' interest rate are positively correlated with the percentage changes in sales and output, with correlation coefficients of 0.22 and 0.16 , respectively.

In addition to the growth rates of sales, output, and real prices, the model makes predictions about the ratios of output to sales and of available supply to sales. Available supply is equal to the stock of inventories at the beginning of the month plus that month's output, and the ratio of available supply to sales is commonly used in the industry as a gauge of how well production and sales are aligned. Over the sample period, we find that both ratios are roughly constant, although quite volatile.

\subsection{Personal disposable income and consumption}

To measure households' income, we use personal disposable income as published by the BEA. As with all our nominal variables, we deflate this income measure with the nondurables consumer price index. We use income to construct two ratios that are important variables in our theoretical model. The first is equal to expenditures on light motor vehicles over income, where expenditures are equal to the average vehicle price multiplied by sales. The second ratio is nonmotor vehicle expenditures over income. For the numerator of this last ratio, we use the personal consumption expenditure data published by the BEA minus our measure of light vehicle expenditure. The ratio of light motor vehicle expenditure over income fluctuates around 0.05 for most of our sample but starts a gradual decline to 0.03 starting around 2000 (see the dotted line in figure 4). Not surprisingly, the ratio of nonmotor vehicle expenditure to income is roughly the mirror image of the ratio of light vehicle expenditure to income.

In our model, available supply, measured as the beginning-of-period stock of inventories plus current production, plays a large role in both the firm's and the household's problem. In equilibrium, changes in available supply have a number of direct and indirect impacts on prices and sales. To gain a rough sense of how available supply, sales, prices, and income fluctuate together, we consider the comovement between the ratios of available supply to sales and of light vehicle expenditures and income. As illustrated in figure 4, these two ratios are negatively correlated, with a correlation coefficient of -0.61 . This suggests that a main force in the model is that manu- 


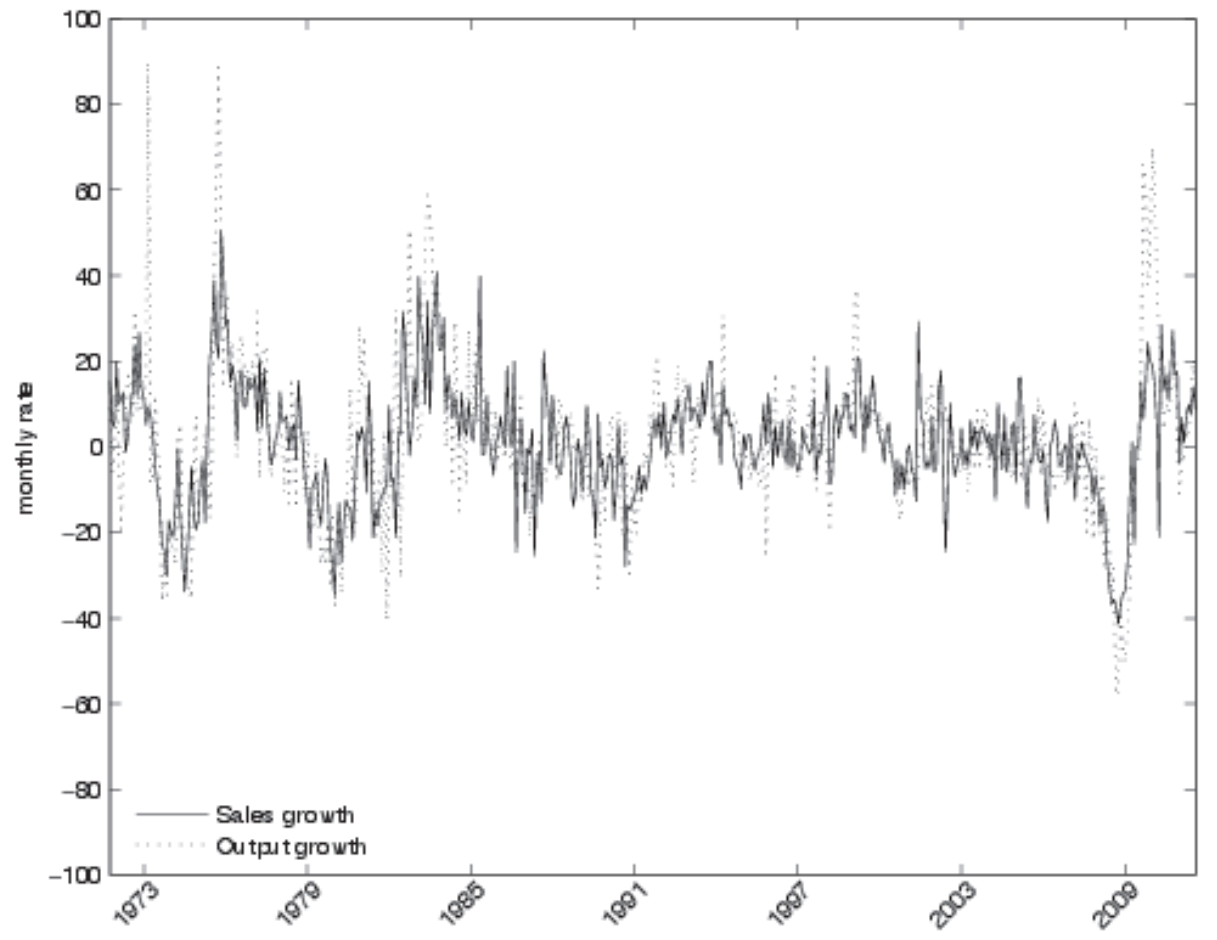

Figure 2: Growth Rates of Sales and Output, 1972-2011

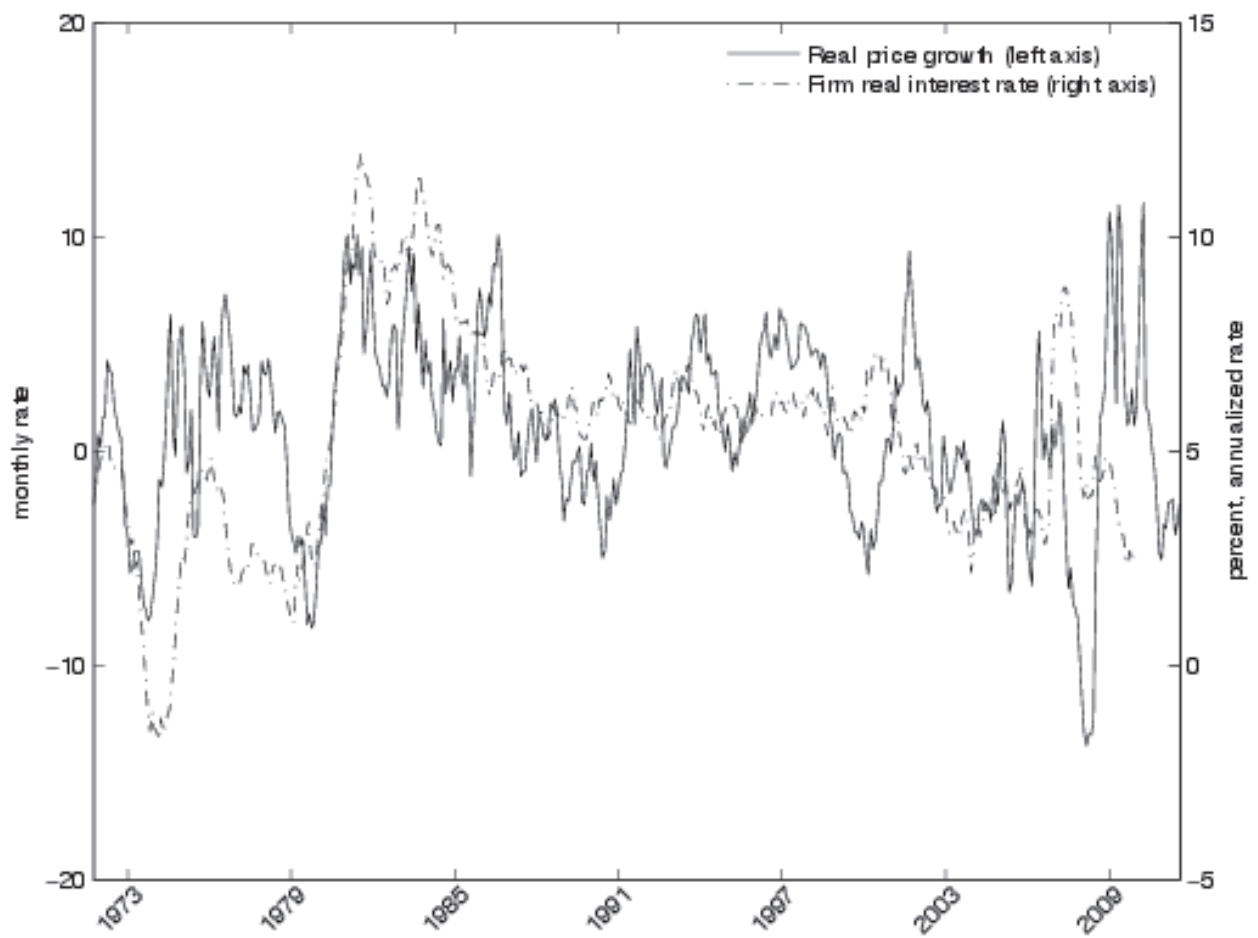

Figure 3: Firm's Real Interest Rates and Real Prices, 1972-2011 


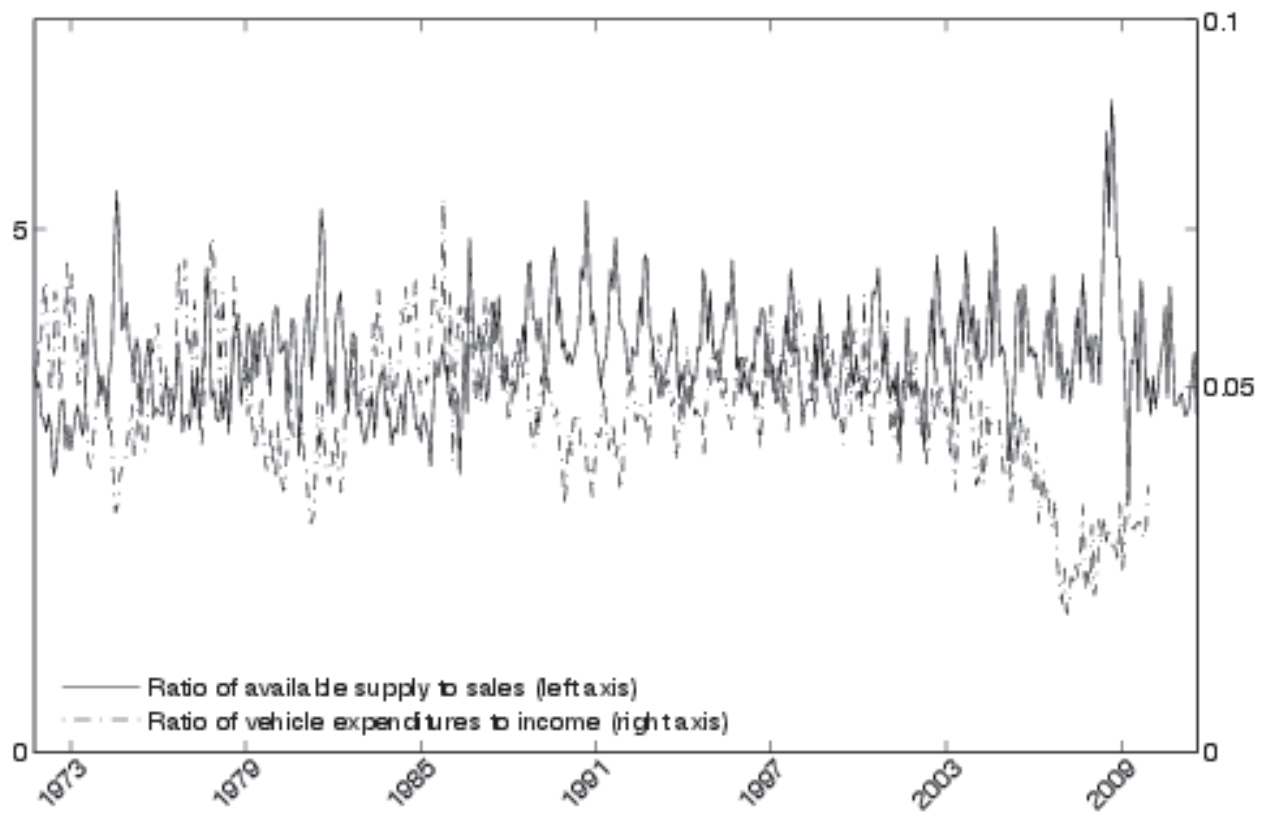

Figure 4: Ratios of Available Supply to Sales and Light Motor Vehicle Expenditure to Income, 1972-2011

facturers use inventories to smooth production, as available supply tends to grow relative to sales when households reduce the amount of income they spend on motor vehicles.

\section{Empirical Results}

In this section, we discuss the methods we used to solve and estimate the model. We also report the estimation results. We then illustrate the mechanics and implications of the model through three sets of impulse-response functions.

\subsection{Solving and estimating the model}

We take the model to the data in two steps. In the first step, we estimate the parameters of the stochastic processes of interest rates, income, and wages independently from the rest of the model. Given these estimated stochastic processes, in the second step we calibrate some parameters and estimate the remainder by taking the model to the data.

We begin by estimating the laws of motion for interest rates (equations 45-49), wages (equation 51), and income (equation 52). To estimate the six parameters in the interest-rate processes, 
we write the five equations in state-space notation:

$$
\begin{aligned}
x_{t+1} & =A x_{t}+C w_{t+1} \\
y_{t} & =G x_{t}
\end{aligned}
$$

where $x_{t}=\left[\begin{array}{ll}f_{t} x_{1 t} x_{2 t}\end{array}\right]^{\prime}, y_{t}=\left[\begin{array}{ll}r_{1 t}-\bar{r}_{1} & r_{2 t}-\bar{r}_{2}\end{array}\right]^{\prime}, w_{t+1}=\left[\eta_{t+1}^{f} \eta_{t+1}^{x_{1}} \eta_{t+1}^{x_{2}}\right]$ and

$$
A=\left[\begin{array}{ccc}
\rho_{f} & 0 & 0 \\
0 & \rho_{x_{1}} & 0 \\
0 & 0 & \rho_{x_{2}}
\end{array}\right], \quad C=\left[\begin{array}{ccc}
0.001 & 0 & 0 \\
0 & \sigma_{\epsilon_{1}} & 0 \\
0 & 0 & \sigma_{\epsilon_{2}}
\end{array}\right], \text { and } \quad G=\left[\begin{array}{ccc}
\phi & 1 & 0 \\
\phi & 0 & 1
\end{array}\right]
$$

Parameter values are estimated by maximizing the likelihood computed using the time-varying Kalman filter, where the data are the monthly household and firm real interest rates described in section 3.1.

The point estimates and standard errors are reported in table 1. All the parameters are tightly estimated. The point estimates highlight the considerable persistence in real interest rates with all three autoregressive coefficients above 0.95. Thus, current high (low) interest rates imply high (low) interest rates for many periods in the future. The estimated processes do a good job of matching the second moments of the two interest rates. The standard deviation of $r_{1}$ and $r_{2}$ in the data are 0.00178 and 0.00198 , respectively; for our estimated specification, they are 0.00198 and 0.00201 . The autocorrelations of $r_{1}$ and $r_{2}$ in the data are 0.987 and 0.988 , respectively; for our estimated specification, they are 0.991 and 0.990 . On average, consumers pay 71 basis points more than firms for credit at an annual rate, although, as we illustrate in figure 1, toward the end of our sample, consumers have, more often than not, paid less. In the data, consumers have paid less for credit than automakers 19.2 percent of the time. In our estimated process, this occurs 19.6 percent of the time. In the data, the contemporaneous correlation between the two interest rates is 0.945 ; in our estimated process, this correlation is 0.942 .

We use BEA data on real disposable income to estimate the process describing the growth rate of income in our model (equation 52). Using least squares, we estimate the growth rate of income to be a fairly persistent process (see table 1). We were not able to find a timeseries of wages for workers in the motor vehicle industry. Although the Bureau of Labor Statistics (BLS) reports wage data, these figures do not account for benefits, which we believe to be a significant fraction of total compensation for motor vehicle workers. The BLS does publish compensation for workers in the durable goods sector. Using least squares, we estimate the stochastic process of real wages in the model using these data. We find that real wages grow at an average monthly rate of 0.0002 and are fairly persistent; the coefficient on lagged real wages is 0.7382 .

Our second step relies on our solving the model. Because it not possible to obtain an analytical solution to the market equilibrium model, we use DYNARE to approximate, solve, and estimate 
Table 1: Parameter Estimates and Standard Errors for the Laws of Motion for Real Interest Rates, Real Income, and Real Wages.

\begin{tabular}{|c|c|c|c|}
\hline & Parameter & $\begin{array}{c}\text { Point } \\
\text { estimate }\end{array}$ & $\begin{array}{l}\text { Standard } \\
\text { error }\end{array}$ \\
\hline \multicolumn{4}{|l|}{ Law of motion for real interest rates } \\
\hline & \multicolumn{3}{|c|}{ household rate } \\
\hline persistence & $\rho_{r_{1}}$ & 0.9548 & 0.0759 \\
\hline standard deviation & \multicolumn{2}{|r|}{ firm rate } & 0.00001 \\
\hline persistence & $\rho_{r_{2}}$ & 0.9643 & 0.0244 \\
\hline standard deviation & $\sigma_{\eta_{2}}$ & 0.0002 & 0.00001 \\
\hline & \multicolumn{3}{|c|}{ common shock to both rates } \\
\hline persistence & $\rho_{f}$ & 0.9919 & 0.0063 \\
\hline impact coefficient & $\phi$ & 0.2444 & 0.0069 \\
\hline \multicolumn{4}{|l|}{ Law of motion for real income } \\
\hline constant & $\bar{I}$ & 0.0002 & 0.00007 \\
\hline persistence & $\rho^{I}$ & 0.8993 & 0.0200 \\
\hline standard deviation & $\sigma_{\eta_{I}}$ & 0.0011 & \\
\hline \multicolumn{4}{|l|}{ Law of motion for real wages } \\
\hline constant & $\bar{W}$ & 0.0002 & 0.0001 \\
\hline persistence & $\rho^{w}$ & 0.7382 & 0.0539 \\
\hline standard deviation & $\sigma_{\eta_{w}}$ & 0.0016 & \\
\hline
\end{tabular}

Note: The standard deviation of the innovation to $f_{t}, \sigma_{\eta_{f}}$, is normalized to 0.001 .

the model. ${ }^{18}$ The basic strategy implemented through DYNARE is to linearize the model through a first-order Taylor approximation around its nonstochastic steady state to obtain a system of linear difference equations. ${ }^{19}$ We then calibrate several parameters such that the model, in steady state, matches several key moments in the data. Finally, we use a Bayesian maximum likelihood procedure to estimate the posterior distributions of the remaining parameters.

We use our model to match the time series of the ratios of light vehicle expenditures to income, available supply to sales, output to sales, and consumption to income, as well as the growth rates of real prices, sales, and output. We calibrate six parameters so that the model, in its initial steady state, closely matches the mean values of our seven data series. We set the return on labor $(\alpha)$, to 0.6 , implying that returns to labor are 60 percent, inline with the macroeconomics literature. We then chose the monthly scrappage rate for vehicles $(\delta)$ to be 0.0041 , which is equal to a 5 percent annual scrappage rate. This rate implies that the median car has a 50 percent chance of

\footnotetext{
${ }^{18}$ For more information on DYNARE, go to http://www.dynare.org/.

${ }^{19}$ See appendix B for a statement of the model as well as the nonstochastic steady state.
} 
Table 2: Calibrated Parameters

\begin{tabular}{lcc}
\hline \multicolumn{1}{c}{ Parameter } & & Value \\
\hline Return on labor & $\alpha$ & 0.6 \\
Vehicle scrappage rate & $\delta$ & 0.0041 \\
Fraction of vehicle loan paid off & $\mu$ & 0.02 \\
Household discount rate & $\zeta$ & 0.995 \\
Fraction of new vehicle purchases financed with a loan & $\bar{\xi}$ & 0.35 \\
Law of motion for real wages, constant term & $\bar{W}$ & 0.0005 \\
\hline
\end{tabular}

surviving 15 years, consistent with estimates in the literature for 1990 model-year vehicles. ${ }^{20}$ We set the percentage of the stock of vehicle loans paid off each month $(\mu)$ to be 0.02 , which roughly implies that the average loan lasts 4 years. This choice is consistent with the household interest rate, which is the rate on a 48-month new car loan. Next, we set households' monthly discount rate $(\zeta)$ to 0.995 .

To calibrate the fraction of new vehicle purchases financed with an auto loan $(\bar{\xi})$, we use equation (41), which demonstrates that in steady state the mean value of the stock of light vehicle loans multiplied by $\mu$ is equal to the mean value of light vehicle expenditures multiplied by $\bar{\xi}$. We have already set $\mu$ to 0.02 and can use the BEA data to compute the mean value of light vehicle expenditures over our sample. We also compute the mean value of the stock of vehicle loans using data published in the Board of Governor's G.19 consumer credit report. Using these numbers, we back out that $\bar{\xi}$ is equal 0.35 .

Finally, we find that the estimated average monthly real wage rate of 0.0002 implies that in steady state the growth rate of real prices is below that of sales. In the data, however, real prices grow faster than sales. To close the gap between the model and the data, we increased the monthly growth rate of real wages $(\bar{W})$ to 0.0005 . A summary of the calibrated parameters is presented in table 2 .

This leaves us with 7 parameters to estimate in addition to the standard deviations of the measurement error terms. We take a Bayesian approach to estimating the model's likelihood and hence specify prior distributions for all the parameters (see table 3 for a list of the prior distributions). Based on the literature, the average own-price demand elasticity for light motor vehicles is around 3. Berry, Levinsohn, and Pakes (1995), for example, report own-price elasticities that range, in absolute value, from 3 to 6, and Goldberg (1995) reports an average (unweighted) elasticity of 3.28. Hence, we characterize the prior for $\varepsilon$ as a normal distribution with a mean of 3 and a standard deviation of 1.0. There is little empirical work that measures the elasticity of sales with respect to available supply, and we therefore set its prior distribution to be normal, with a mean of 3 and a standard deviation of 1.0 .

\footnotetext{
${ }^{20}$ Section 5.5 of Bandivadekar et al. (2008) provide a review of the literature focused on estimating scrappage rates of light vehicles. Note that 1990 is about the midpoint of our sample.
} 
The growth rate of productivity is characterized by three parameters. The constant term is set to 0.0002 (or 0.2 percent annual growth rate) and is not estimated. The prior distribution of the persistence term is assumed to be a Beta distribution centered at 0.75 , and we chose an inverse gamma prior for the standard deviation of the error term with a mean of 0.01. For the two terms characterizing the costs of holding inventory $\left(\kappa_{0}, \kappa_{1}\right)$, we chose priors with normal distributions with means of 0.1 and 0.8 , respectively. Finally, we normalize the utility weight on consumption $\left(\pi_{1}\right)$ to 1 and chose a prior distribution for the utility weight on motor vehicle consumption $\left(\pi_{2}\right)$ to be inverse gamma, with a mean of 0.1 and standard deviation of 0.1 . With these chosen values, the steady state of our model closely matches the mean values of the variables in the data that we are trying to match.

Summarizing, we have three sets of parameters, $\left(\Theta_{1}, \Theta_{2}, \Theta_{3}\right)$, where $\Theta_{1}$ is the set of parameters estimated in the first step described at the beginning of this section; $\Theta_{2}$ is the set of calibrated parameters (listed in table 2); and $\Theta_{3}$ is the set of parameters estimated by Bayesian maximum likelihood. Formally, letting $\left\{X_{t}\right\}_{t=1}^{T}$ denote the data, the posterior distribution is given by

$$
P\left(\Theta_{3} ;\left\{X_{t}\right\}_{t=1}^{T}, \Theta_{1}, \Theta_{2}\right) \propto p\left(\Theta_{3}\right) L\left(\left\{X_{t}\right\}_{t=1}^{T} ; \Theta_{1}, \Theta_{2}, \Theta_{3}\right),
$$

where $p$ denotes the prior distributions of the parameters in $\Theta_{3}$ and $L$ denotes the likelihood. The posterior distributions of the parameters are estimated using the suite of programs available in DYNARE. We chose a Markov chain Monte Carlo (MCMC) approach, which used a MetropolisHastings algorithm. Two independent Markov chains were used with average acceptance rates of 23 and 22 percent, respectively, and the MCMC diagnostics demonstrated that the draws from the posterior distributions of all parameters converged.

In table 3, we report moments of both the prior and the posterior distributions of the parameters in $\Theta_{3}$. The estimated posterior distributions on the two elasticity parameters yield sensible results. The $\varepsilon$ parameter, which is the own-price elasticity of the demand for a new vehicle, has a mean of 2.66 in absolute value and lies in the credible interval of $(1.56,3.84)$. This is consistent with the literature reviewed earlier. The $\theta$ parameter, which is the available supply elasticity of the demand for a new vehicle, is estimated have a mean of 3.09 and so is slightly greater than the own-price elasticity. ${ }^{21}$

The estimates of $\kappa_{0}$ and $\kappa_{1}$ imply that inventory holding costs are increasing and convex (see equations (20) and (21)). Although it is difficult to interpret these two parameter values, their impact on manufacturers' behavior can be seen in the next section, which analyzes how households and firms react to various interest-rate shocks. Finally, we estimate that productivity

\footnotetext{
${ }^{21}$ Copeland, Dunn, and Hall (2011) estimate a similar elasticity (how changes in an inventory-based variety measure increase sales) to be roughly 0.5. Their discrete-choice static model identifies this elasticity from the variation in the cross-section, whereas in the current paper the available supply elasticity is pinned down by the steady state, specifically, by the mean values of the ratios of available supply to sales and output to sales.
} 
Table 3: Prior and Posterior Distributions of Estimated Parameters

\begin{tabular}{lc|ccc|cc}
\hline Parameter & & \multicolumn{3}{|c|}{ Prior } & \multicolumn{2}{c}{ Posterior } \\
& & mean & std dev & distribution & mean & credible interval \\
\hline Available supply elasticity & $\theta$ & 3.0 & 1.0 & normal & 3.09 & $(1.90,4.38)$ \\
Own-price elasticity & $\varepsilon$ & 3.0 & 1.0 & normal & 2.66 & $(1.56,3.84)$ \\
Linear inventory cost & $\kappa_{0}$ & 0.1 & 0.05 & normal & 0.11 & $(0.06,0.15)$ \\
Nonlinear inventory cost & $\kappa_{1}$ & 0.8 & 0.2 & normal & 0.57 & $(0.27,0.85)$ \\
Utility weight on motor vehicle & $\pi_{2}$ & 0.1 & 0.1 & inverse gamma & 0.10 & $(0.09,0.10)$ \\
expenditures & & & & & & \\
Persistence in productivity growth & $\gamma_{\rho}$ & 0.75 & 0.15 & beta & 0.59 & $(0.52,0.65)$ \\
$\begin{array}{l}\text { Standard deviation of productivity } \\
\text { growth }\end{array}$ & $\eta_{\gamma}$ & 0.01 & $\infty$ & inverse gamma & 0.004 & $(0.003,0.004)$ \\
\hline
\end{tabular}

\begin{tabular}{l|cccc|cc}
\hline $\begin{array}{l}\text { Standard deviations on measurement } \\
\text { errors }\end{array}$ & \multicolumn{3}{|c|}{ Prior } & \multicolumn{2}{c}{ Posterior } \\
& mean & std dev & distribution & mean & credible interval \\
\hline Ratio of new vehicle expenditure to & 0.01 & $\infty$ & inverse gamma & 0.01 & $(0.01,0.01)$ \\
income & & & & & \\
Ratio of consumption to income & 0.01 & $\infty$ & inverse gamma & 0.01 & $(0.01,0.01)$ \\
Ratio of available supply to sales & 0.5 & $\infty$ & inverse gamma & 0.51 & $(0.49,0.54)$ \\
Ratio of output to sales & 0.1 & $\infty$ & inverse gamma & 0.14 & $(0.14,0.15)$ \\
Growth rate of real sales & 0.01 & $\infty$ & inverse gamma & 0.01 & $(0.01,0.01)$ \\
Growth rate of real output & 0.01 & $\infty$ & inverse gamma & 0.01 & $(0.01,0.01)$ \\
\hline
\end{tabular}


Table 4: Data and Model Moments

\begin{tabular}{|c|c|c|c|}
\hline \multirow[t]{2}{*}{ Time-series } & \multirow{2}{*}{$\begin{array}{l}\text { Data } \\
\text { mean }\end{array}$} & \multicolumn{2}{|c|}{ Model } \\
\hline & & mean of the mean & std of the mean \\
\hline Ratio of new vehicle expenditures to income & 0.047 & 0.045 & 0.003 \\
\hline Ratio of consumption to income & 0.953 & 0.953 & 0.003 \\
\hline Ratio of available supply to sales & 3.769 & 3.736 & 0.025 \\
\hline Ratio of output to sales & 1.007 & 1.001 & 0.007 \\
\hline Growth rate of real prices (annual rate, percent) & 1.038 & 2.161 & 0.755 \\
\hline Growth rate of sales (annual rate, percent) & 0.234 & 0.438 & 0.849 \\
\hline Growth rate of output (annual rate, percent) & 0.219 & 0.432 & 0.930 \\
\hline & std & mean of the std & std of the std \\
\hline Ratio of new vehicle expenditures to income & 0.010 & 0.007 & 0.001 \\
\hline Ratio of consumption to income & 0.010 & 0.007 & 0.001 \\
\hline Ratio of available supply to sales & 0.507 & 0.508 & 0.017 \\
\hline Ratio of output to sales & 0.146 & 0.144 & 0.005 \\
\hline Growth rate of real prices (annual rate) & 4.399 & 14.232 & 0.437 \\
\hline Growth rate of sales (annual rate) & 14.765 & 11.542 & 0.484 \\
\hline Growth rate of output (annual rate) & 19.670 & 16.116 & 0.556 \\
\hline
\end{tabular}

Note: std is standard deviation. Model is the simulated data generated by the model. The first and second moments of the variables in the simulated data are computed from 1,000 simulated datasets.

is a somewhat persistent process and that the standard deviation of productivity growth is less than 0.005 .

\subsection{Goodness of fit}

Before using the model to analyze how interest rates influence households' and firms' decision making, we demonstrate that the estimated model fits the data well using two different approaches. We first consider how well data generated by the model matches the first two moments of variables in our actual data. To do this, we simulate the model so as to generate 1,000 panel datasets of the same size as our actual data. These simulated datasets mimic our actual data, in that they capture the comovements of the growth rates of sales, real prices, and output as well as the ratios of new vehicle expenditures to income, consumption to income, available supply to sales, and output to sales. Using the actual data, we compute the mean and standard deviation of each variable. Using the simulated data sets, we first compute the mean and standard deviation of each variable for each data set. We then look at the distribution of each of these moments and report their mean and standard deviation in table 4.

As illustrated in the table, the model does well in matching the first and second moments of the ratios. The model slightly overpredicts the mean growth rates of real prices, sales, and output and generates a more volatile time series of the growth rate of real prices, as evidenced by the 
much larger standard deviation in the simulated data (14.232 versus 4.399). However, the model captures reasonably well the standard deviations of the growth rates of sales and output (see the last two rows of table 4).

Our second goodness-of-fit measure compares impulse-response functions generated by a recursive vector autoregression (RVAR). In the empirical literature, researchers have used structural VARs to estimate the response of real variables to innovations in interest rates. A challenge with this type of analysis is properly identifying the causal impact of changes to interest rates on real variables such as output or sales. One approach is to make an identifying assumption based on timing, whereby the contemporaneous real variables can respond to an interest-rate innovation only with a lag (e.g., see Bernanke and Blinder (1992)). This approach allows for the estimation of RVARs, which seek to measure the impact of an innovation to interest rates on real variables (see Ludvigson (1998) for an example of such an approach applied to the motor vehicle industry). In the spirit of these papers, we estimate a 6 variable RVAR with 4 lags where the order of the variables is index of industrial production, consumer price index, production price index, ratio of available supply to sales, ratio of output to sales, and firms' interest rate. ${ }^{22}$ The three indexes capture macroeconomic trends, and the two ratios are the variables of interest. We then calculate the impulse responses of the two ratios to a one-standard-deviation positive innovation to firms' interest rate (see panel A of figure 5)

To determine how well the model matches these estimated impulse-response functions, we estimate a RVAR on the simulated data. Mimicking the RVAR that we estimated on the data, this is a 3 variable RVAR with 4 lags, where the variables and their order are ratio of available supply to sales, ratio of output to sales, and firms' interest rate. ${ }^{23}$ The order of these variables matches the RVAR estimated on the data, and we do not include the macroeconomic variables because our model does not generate business cycle trends. For each of the 1,000 simulated data sets, we estimate this RVAR and calculate the impulse response of the two ratios to an innovation to firms' interest rate, as well as the deviation of firms' interest rate from the steady-state value. We then average across the 1,000 impulse responses to arrive at an average estimated impulse response (see panel B of figure 5).

The equilibrium responses of the ratios of available supply to sales and output to sales have the same dynamics across the two RVARs, strong evidence that our model is capturing well the impact of changes in interest rates faced by vehicle manufacturers. The RVARs from the simulated data, however, do predict smaller responses of these two ratios to the interest-rate innovation, roughly an order of magnitude less. Almost identical results arise from a one-standard-deviation

\footnotetext{
${ }^{22}$ The consumer price index is for all urban consumers, and the producer price index is for all commodities; both series are published by the Bureau of Labor Statistics. We smoothed both the ratios using a moving average, which for a given date $t$, used data from $t-6$ to $t+6$.

${ }^{23}$ Following how we treated the data, we smoothed the data on ratios using a moving average, which for a given date $t$, used data from $t-6$ to $t+6$.
} 


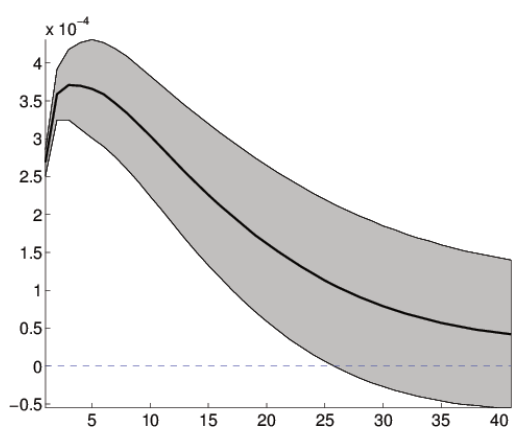

firm interest rate

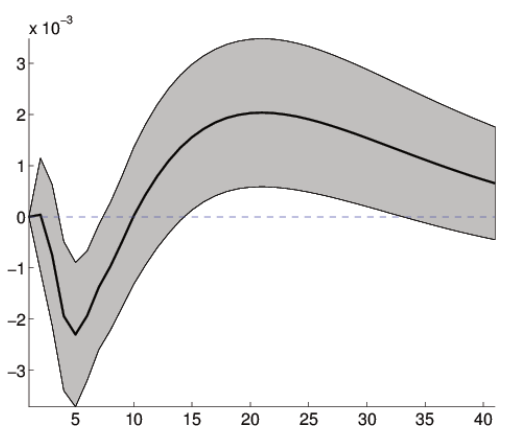

ratio of output to sales

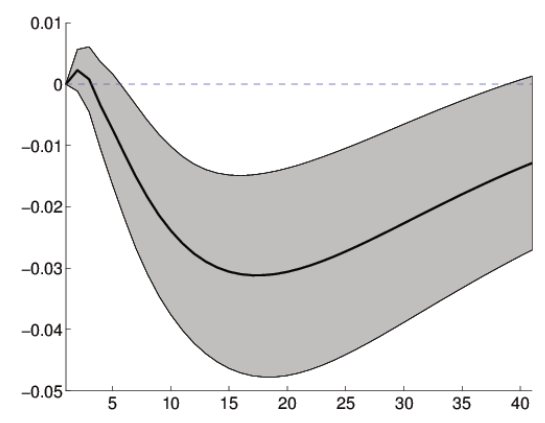

ratio of available supply to sales

Panel A: Data: Shock to Firms' Interest Rate

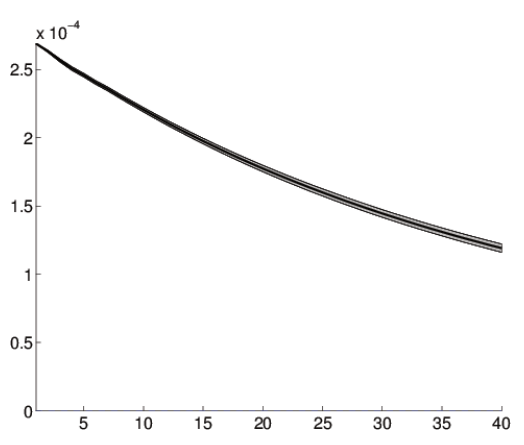

firm interest rate

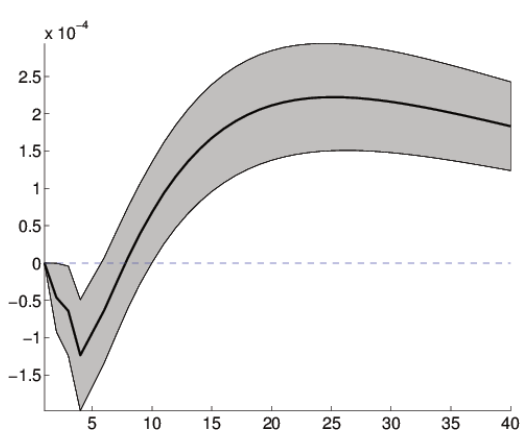

ratio of output to sales

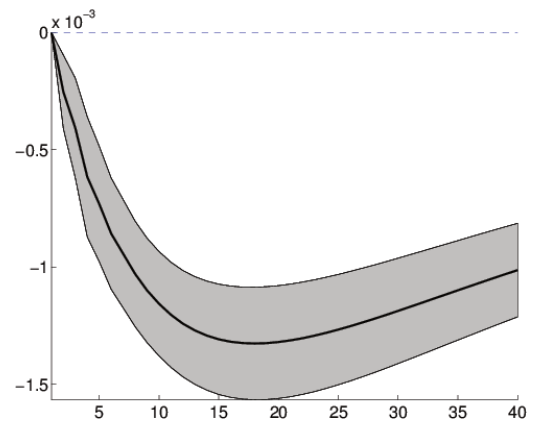

ratio of available supply to sales

Panel B: Model: Shock to Firms' Interest Rate

Figure 5: Recursive Impulse Responses on the Output to Sales and Available Supply to Sales Ratios to a One-Standard-Deviation Interest-Rate Shock

Note: The bands around the impulse responses are 95 percent confidence intervals. 
shock to the household interest rate. For the sake of brevity, these results are not presented here.

\subsection{Impulse-response functions}

With our estimated parameters, we analyze the impact of innovations to real interest rates on equilibrium real prices, sales, output, and inventories. Most important, we measure how interestrate shocks to households affect vehicle sales, output, and inventories as well as interest rate shocks to manufacturers. Furthermore, our equilibrium model allows both households and manufacturers to react to changes to either interest rate. As discussed in the introduction, this approach builds on the existing literature, which has focused on either the household side or the manufacturer side.

We begin by considering an innovation to households' interest rate and manufacturers' interest rate separately. For each 100 basis-point rate increase, we use impulse-response functions to trace the impact on the growth rates of sales, real prices, and output as well as the ratios of new vehicle expenditures to income, available supply to sales, and output to sales. To aid in interpreting the quantitative magnitude of each response, we center each response on its mean. Using this same approach, we then examine the equilibrium responses when there is a shock to the common component of both rates.

A 100 basis-point increase in a household's interest rate increases the cost of borrowing $\$ 25,000$ (say, to purchase a $\$ 30,000$ car) over 4 years by $\$ 11$ per month or $\$ 528$ over the life of the loan. Thus the demand for new vehicles will decline. As illustrated in figure 6 , sales fall immediately as the growth rate of sales falls from its mean of 0.43 percent per year to less than -1.00 percent in the first two months following the shocks. This is a large response. Given that roughly 17 million cars and light trucks are currently sold in the United States each year, a drop of 1 percent is 170,000 cars per year or 14,000 per month. After 6 months, the market does eventually recover, as the growth rate of sales exceeds its steady-state value and then drops back to its steady state. The model also captures manufacturers' response to this interest-rate shock. Reacting to the persistently lower demand from households, the representative manufacturer looks to lower its available supply by cutting prices and output. The manufacturer's response is large and immediate. To dampen the decline in sales, manufacturers lower prices by more than 2 percent in the period immediately following the shock and output is cut by 6 percent. Since the decline in output is greater than that of sales, the ratios of output to sales and available supply to sales both fall.

The decline in available supply has a secondary, negative impact on sales because its decline raises the household's shopping cost. Hence, the manufacturer's response amplifies and propagates the demand-dampening effects of a rise in the household interest rate. This equilibrium effect, along with the persistence in the household interest rate, causes the growth rate of sales to recover only slowly to its steady-state value, despite the much quicker reversion to the steady state of the real price and output growth rates. 


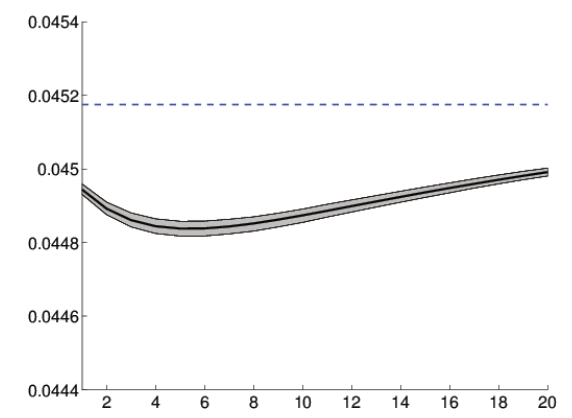

ratio of new vehicle expenditures to income

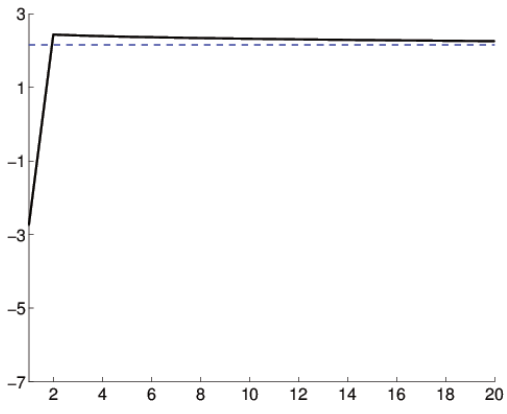

growth rate of real prices

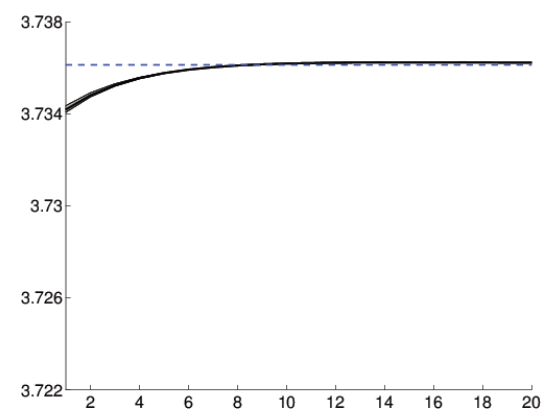

ratio of available supply to sales

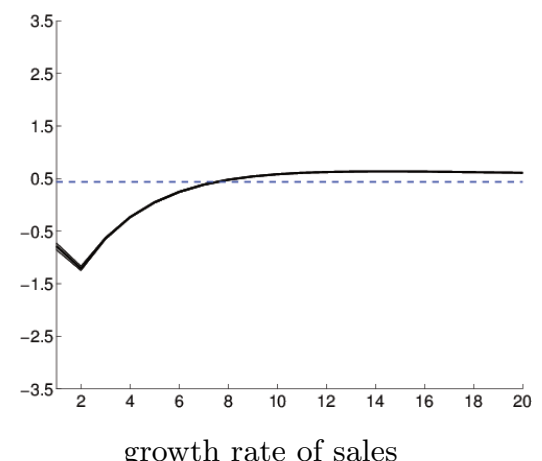

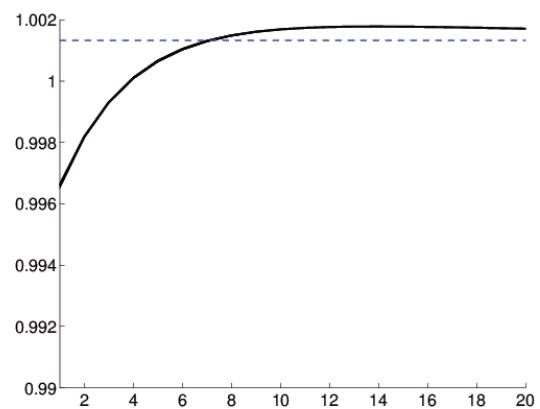

ratio of output to sales

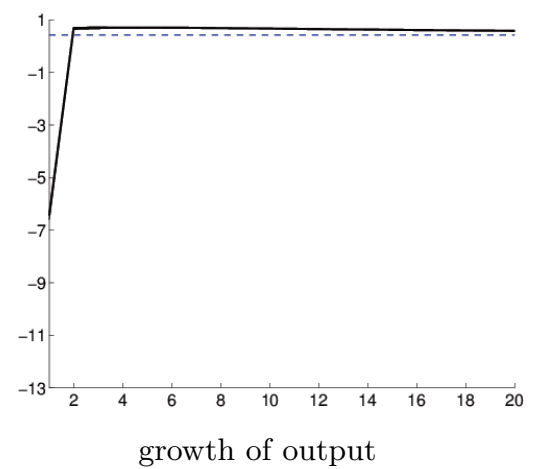

Figure 6: Impulse Response to a 100 Basis-Point Positive Shock to Households' Interest Rate

Note: Each impulse response is centered on its mean, represented by the dashed line. The growth rates of real prices, sales, and output are reported at an annual rate. The bands around the impulse responses are 95 confidence intervals. 


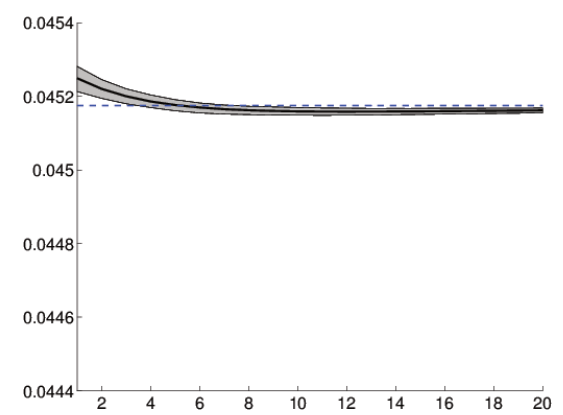

ratio of new vehicle expenditures to income

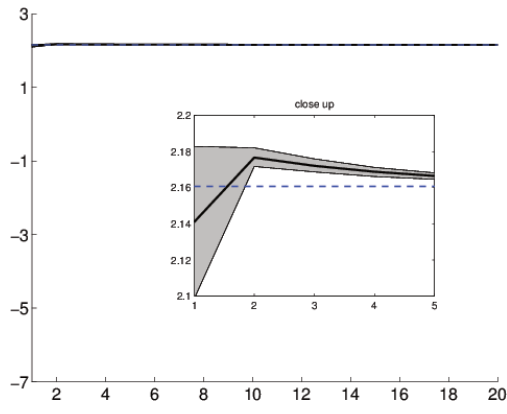

growth rate of real prices

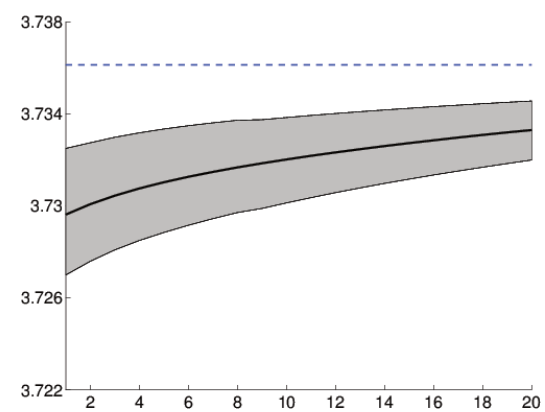

ratio of available supply to sales

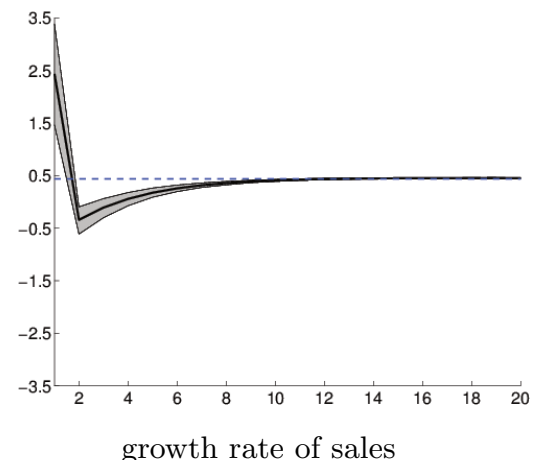

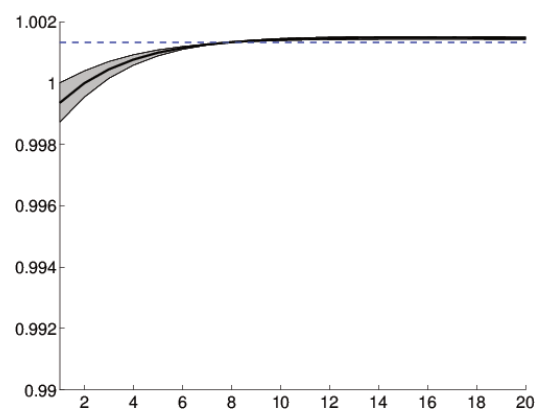

ratio of output to sales

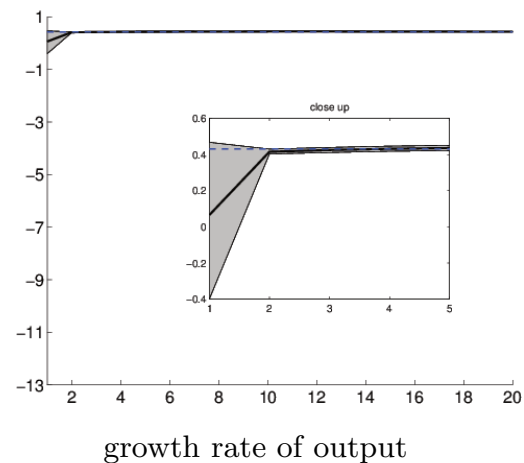

Figure 7: Impulse Response to a 100 Basis-Point Positive Shock to Firms' Interest Rate

Note: Each impulse response is centered on its mean, represented by the dashed line. The growth rates of real prices, sales, and output are reported at an annual rate. The bands around the impulse responses are 95 confidence intervals. 
In figure 7, we report the responses to a 100 basis-point increase in manufacturers' interest rates, which raises their cost of holding inventories. To more easily compare the quantitative impact of this shock to the 100 basis-point shock to the household interest rate, we hold fixed the scale of the impulse-response functions. Because the price and output growth rate responses are small, we included close-ups for these two graphs.

To put the 100 basis-point rate increase to the manufacturer in perspective, if a dealer finances a $\$ 30,000$ car, it raises her inventory holding costs by $\$ 25$ per month. For a dealer who keeps 200 vehicles in stock, a 100 basis-point increase raises total holding costs by $\$ 5,000$ per month. With a desire to lower available supply, manufacturers and dealers immediately lower output growth, to reduce available supply. Theoretically, the impact on sales growth is ambiguous since there are two countervailing forces at work; although dampening price growth boosts sales, the decline in available supply, by increasing household shopping costs, reduces sales. At the estimated parameter values, the model predicts that on net sales growth spikes up in the initial period after the interest-rate innovation, before falling below its steady-state value in the second period and then slowly returning to steady state. The price impact is small, but its effect on sales is boosted by dynamic nature of the household's problem. Consumers recognize that the manufacturer is providing a temporary price cut (see the close up in the figure related to the growth rate of real prices), and so intertemporally substitute, shifting their vehicle purchases to period 1 from periods 2, 3, 4, and so on. (This same dynamic also occurs in the previous impulse-response exercise, where the household interest rate was shocked.) Manufacturers' and households' actions result in ratios of output to sales and available supply to sales that fall below their steady-state values and slowly recover. Furthermore, the ratio of new vehicle expenditures to income is positively shocked and remains above its steady-state value for 4 months.

The different responses to innovations to households' and to firms' interest rates can be seen by comparing figures 6 and 7. In particular, the 100 basis point shock to households' interest rate has a much larger negative impact on price and output growth than the 100 basis-point shock to manufacturers' interest rate. The response of sales growth also differs across the two exercises. When households' interest rate is shocked, sales growth falls in the first period and remains negative for 8 months. Whereas when manufacturers' interest rate is shocked, sales growth initially spikes up and then falls below its steady-state value. A final difference across these two exercises is highlighted by the impulse response of the ratio of new vehicle expenditures to income. In response to an increase in households' interest rate, this ratio drops and only slowly reverts to its steady state (see the northwest panel in figure 6). In contrast, the increase in manufacturers' interest rate causes an initial jump in this ratio as manufacturers seek to shed inventories to lower available supply (see the northwest panel in figure 7).

Finally, we consider a 100 basis-point positive shock to both households' and manufacturers' interest rates, such as would occur under a restrictive monetary policy (see figure 8 and note 


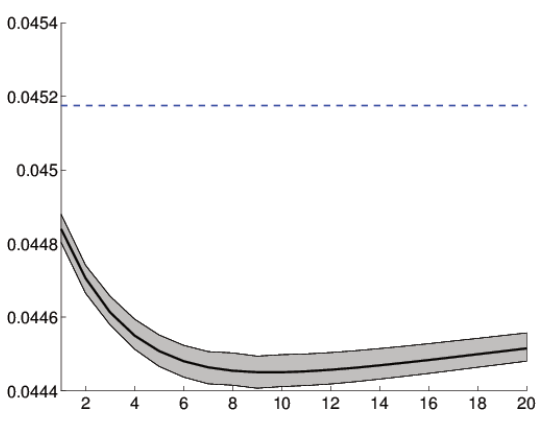

ratio of new vehicle expenditures to income

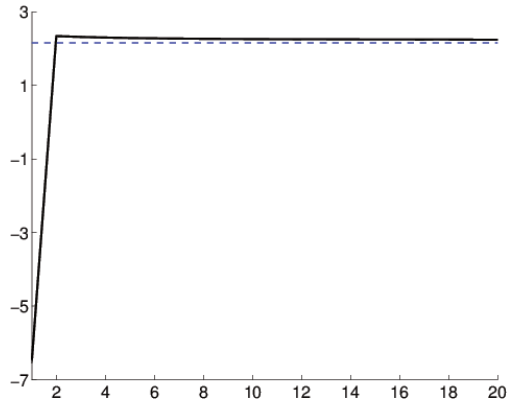

growth rate of real prices

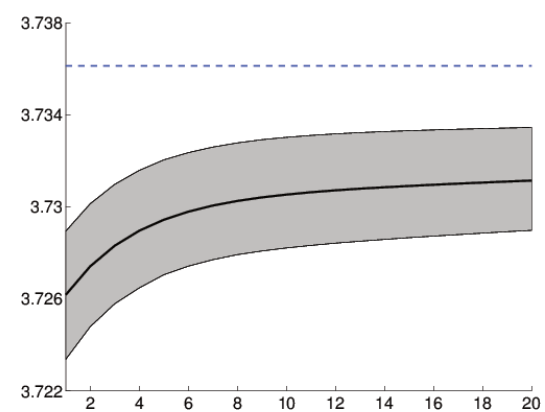

ratio of available supply to sales

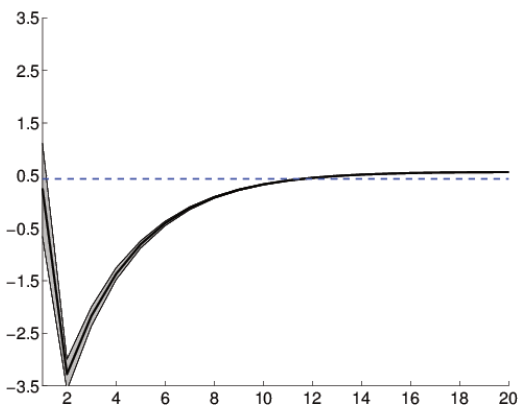

growth rate of sales

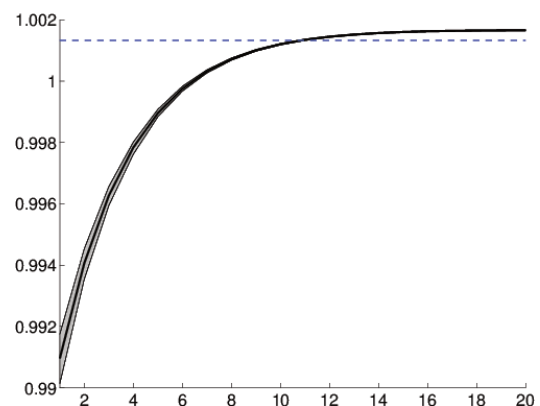

ratio of output to sales

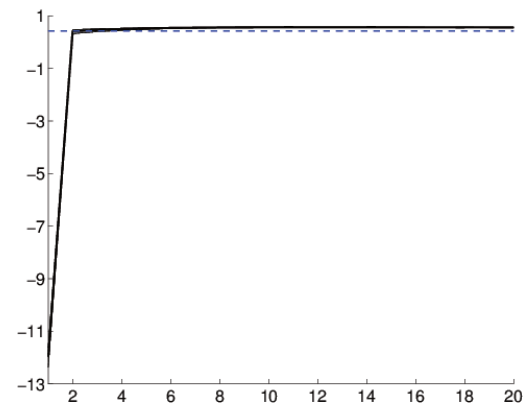

growth of output

Figure 8: Impulse Response to a Shock to the Common Component of Interest Rates, Where the Shock Generates a 100 Basis-Point Innovation to both Interest Rates

Note: Each impulse response is centered on its mean, represented by the dashed line. The growth rates of real prices, sales, and output are reported at an annual rate. The bands around the impulse responses are 95 confidence intervals.

we continue to hold fixed the scale of the impulse-response functions). Formally, we consider a shock to the common component of the interest rate processes $\left(f_{t}\right)$, where the size of the shock is chosen such that the initial innovation to both the interest rates is 100 basis-points. This allows for a easy comparison of the resulting impulse-response functions with the previous two sets of impulse-response functions. Note that although the size of the innovations to the interest rates is similar across these impulse response exercises, their persistence varies. Specifically, the persistence of the common shock, at 0.9919, is greater than the persistence of the household and manufacturer interest rate (see table 1 ).

The responses of households and manufacturers to this common interest-rate shock reinforce one another along some dimensions, while offsetting each other along others. As expected, the model predicts that the shock to the common component of interest rates leads to output and price growth below their steady-state values. Output falls nearly 12 percent at an annual rate in the period immediately following the shock, which translates into a decline of 170,000 light 
vehicles produced in that month. Interestingly, sales growth is initially close to its steady-state value, as the demand-dampening effect of higher household rates is offset by the manufacturer's desire to shed inventories through lower prices. Sales then fall at an annual rate of 3.25 percent in the second month after the interest-rate shock and then slowly revert to the steady-state value. Reflecting the dynamics of sales and price growth, the ratio of new vehicle expenditures to income falls in the initial period and remains below its steady-state value for many periods. As with the previous excerises where households' and manufacturers' interest rates were increased separately, the increase the common component of interest rates leads to a decline in both the ratio of output to sales and the ratio of availalble supply to sales. Moreover, the decline in both ratios from the increase in the common component is quantitatively larger than the decline in both ratios from separate increases in the households' and manufacturers' interest rates, reflecting the fact that the responses are re-inforcing.

\section{Conclusion}

For the past six and a half years, the Federal Reserve has kept interest rates in the United States at near-historic lows. Eventually, interest rates will return to their long-run averages. Thus both policy makers and the public are once again asking one of the classic questions in monetary economics: what is the impact of rising interest rates on the real economy? Part of the answer to this question centers on the durable goods sector. It is well known that durable goods are much more interest-rate sensitive than are nondurable goods or services. In this paper, we focus on the market for new cars and light trucks, which constitute over 25 pecent of durable-goods expenditures in the United States. For this market, we describe two channels through which changes in interest rates operate:

- A household expenditure channel: An increase in the interest rate faced by households increases the cost of financing the purchase of a new automobile, thus decreasing the demand for new cars and light trucks.

- A firm inventory channel: An increase in the interest rate raises the cost to the firm of holding inventories of new cars and light trucks. To reduce inventories, firms decrease prices to stimulate sales and reduce current production. Since consumer demand is itself a function of vehicles available for sale, the decrease in inventories and reduction in output reduce the available supply of new automobiles. This dampens demand and further propagates the impact of the increase in interest rates.

Within the framework of a dynamic model of the market for new automobiles, we find evidence of the impact of interest-rate changes operating through both channels. 
Finally, we recognize that there exists an additional channel through which interest-rate changes affect the auto industry. Automobile manufacturers hold work-in-progress and raw material inventories as well as finished-goods inventories. Introducing work-in-progress and rawmaterial inventories into the model would allow for an analysis of the effects of changes in real interest rates on total inventory holdings, not just those of finished automobiles. We leave incoporating this channel into the model for future work. 


\section{References}

Adda, J. Cooper, R., 2006. "The Dynamics of Car Sales: A Discrete Choice Approach." Manuscript, May.

Alessie, R. Devereux, M. Weber, G., 1997. "Interetemporal Consumption, Durables, and Liquidity Constraints: A Cohort Analysis." European Economic Review 41, 37-59.

Attanasio O., Goldberg P., Kyriazidou E., 2008. "Credit Constraints In The Market For Consumer Durables: Evidence From Micro Data On Car Loans." International Economic Review 49(2), 401-436.

Baines, A., Courchane M., 2013. "Automotive Finance: Will Dealership Finance Reserve go the way of Mortgage Yield Spread Premiums?" Charles River Associates.

Bandivadekar A., Bodek K., Cheah L., Evans C., Groode T., Heywood J., Kasseris E., Kromer M., Weiss M., 2008. "On the Road in 2035: Reducing Transportation's Petroleum Consumption and GHG Emissions." MIT's Laboratory for Energy and the Environment Report No. LFEE 2008-05 RP.

Bernanke, B., Blinder, A., 1992. "The Federal Funds Rate and the Channels of Monetary Transmission." American Economic Review 82(4), 901-921.

Berry S., Levinsohn J., Pakes A., 1995. "Automobile Prices in Market Equilibrium." Econometrica 63(4), 841-890.

Bils M., Kahn J., 2000. "What Inventory Behavior Tells Us about Business Cycles." American Economic Review 90, 458-481.

Blanchard O., 1983. "The Production and Inventory Behavior of the American Automobile Industry." Journal of Political Economy 91, 365-400.

Blanchard O., Melino A., 1986. "The Cyclical Behavior of Prices and Quantities: The Case of the Automobile Market." Journal of Monetary Economics 17, 379-407.

Blinder A., Maccini L., 1991. "Taking Stock: A Critical Assessment of Recent Research on Inventories." Journal of Economic Perspectives 5, 73-96.

Bresnahan, T., Ramey, V., 1994. "Output Fluctuations at the Plant Level." Quarterly Journal of Economics 109(3), 593-624.

Chah, E., Ramey, V., Starr, R. 1995. "Liquidity Constraints and Interetemporal Consumer Optimization: Theory and Evidence from Durable Goods." Journal of Money, Credit and Banking $27,272-287$. 
Chen, J., Esteban, S., Shum, M. 2013. "When do Secondary Markets Harm Firms?" American Economic Review 103(7), 2911-2934.

Copeland, A., 2014. "Intertemporal Substitution and New Car Purchases." RAND Journal of Economics 45, 624-644.

Copeland, A., Dunn, W., Hall, G. 2011. "Inventories and the Automobile Market." RAND Journal of Economics 42, 121-49

Copeland, A., Hall, G., 2011. "The Response of Prices, Sales, and Output to Temporary Changes in Demand." Journal of Applied Econometrics 26, 232-269

Eberly, J., 1994. "Adjustment of Consumers' Durables Stocks: Evidence from Automobile Purchases." Journal of Political Economy 102(3), 403-436.

Esteban, S., Shum, M. 2007. "Durable-Goods Oligopoly with Secondary Markets: The Case of Automobiles." RAND Journal of Economics 38(2), 332-54.

Goettler, R., Gordon, B., 2009. "Does AMD Spur Intel to Innovate More?" Journal of Political Economy 119(6), 1141-1200.

Goldberg, P., 1995. "Product Differentiation ad Oligopoly in International Markets: The Case of the U.S. Automobile Industry." Econometrica 63(4), 891-951.

Jung, H., Yun, T., 2007. "Inventory and Dynamic Effects of Monetary Policy Shocks." Manuscript, November.

Kahn J., 1992. "Why is Production More Volatile than Sales? Theory and Evidence on the Stockout-Avoidance Motive for Inventory-Holding." Quarterly Journal of Economics 109(3), $565-92$.

Kashyap A., Wilcox D., 1993. "Production and Inventory Control at the General Motors Corporation during the 1920's and 1930's." American Economic Review 83, 383-401.

LaReau J., 2013. "Interest Rates Spike Would Trim Inventories: The Industry Could Live with a Modest Increase.” Automotive News July 15, 2013.

Ludvigson S., 1998. "The Channel of Monetary Transmission to Demand: Evidence from the Market for Automobile Credit." Journal of Money, Credit and Banking 30, 365-383.

Maccini L., Moore B., Schaller H., 2004. "The Interest Rate, Learning, and Inventory Investment." American Economic Review 94, 1303-1327. 
Maccini L., Moore B., Schaller H., 2015. "Inventory Behavior with Permanent Sales Shocks." Journal of Economic Dynamics and Control 53, 290-313.

Maccini L., Pagan A., 2013. "Inventories, Fluctuations and Business Cycles." Macroeconomic Dynamics 17(1), 89-122.

Nair, H. 2007. "Intertemporal Price Discrimination with Forward-Looking Consumers: Application to the US market for Console Video-Games." Quantitative Marketing and Economics 5(3), 239-92.

Ramey V., Vine D., 2006. "Declining Volatility in the U.S. Automobile Industry." American Economic Review 96, 1876-1889.

Ramey V., West K.D., 1999. "Inventories." in Handbook of Macroeconomics, J.B. Taylor, M. Woodford (eds.), Amsterdam: North-Holland.

Schiraldi P., 2011. "Automobile Replacement: a Dynamic Structural Approach.” RAND Journal of Economics 42(2), 266-291. 


\section{APPENDIX A: DERIVATION OF THE DEMAND FUNCTION FOR NEW AUTOMOBILES}

(for online publication only)

The household is assumed to choose $S_{j t}$ to minimize shopping costs (equation (2)) subject to the definition of aggregate sales, (equation (3)). The first-order condition is

$$
\left[1+\phi\left(\frac{A_{j t}}{A_{t}}\right)\right] P_{j t}=\lambda_{t}^{s c}\left(\frac{S_{j t}}{S_{t}}\right)^{-\frac{1}{\varepsilon}} .
$$

where $\lambda_{t}^{s c}$ is the multiplier associated with aggregate sales. Solving equation (56) yields

$$
\frac{S_{j t}}{S_{t}}=\left(\frac{P_{j t}}{\lambda_{t}^{s c}}\right)^{-\varepsilon}\left[1+\phi\left(\frac{A_{j t}}{A_{t}}\right)\right]^{-\varepsilon} .
$$

Now, assume that shopping costs are $\phi\left(\frac{A_{j t}}{A_{t}}\right)=\left(\frac{A_{j t}}{A_{t}}\right)^{\nu}-1$. Then, the demand function for new automobiles is

$$
\frac{S_{j t}}{S_{t}}=\left(\frac{P_{j t}}{\lambda_{t}^{s c}}\right)^{-\varepsilon}\left(\frac{A_{j t}}{A_{t}}\right)^{-\varepsilon \nu} .
$$

To solve for $\lambda_{t}^{s c}$, take the definition of aggregate sales

$$
S_{t}=\left[\int_{0}^{1} S_{j t}^{\frac{\varepsilon-1}{\varepsilon}} d j\right]^{\frac{\varepsilon}{\varepsilon-1}}
$$

and substitute equation (58) into equation (59) to get

$$
\begin{aligned}
S_{t} & =\left[\int_{0}^{1} S_{j t}^{\frac{\varepsilon-1}{\varepsilon}} d j\right]^{\frac{\varepsilon}{\varepsilon-1}} \\
& =\left[\int_{0}^{1}\left[S_{t}\left(\frac{P_{j t}}{\lambda_{t}^{s c}}\right)^{-\varepsilon}\left(\frac{A_{j t}}{A_{t}}\right)^{-\varepsilon \nu}\right]^{\frac{\varepsilon-1}{\varepsilon}} d j\right]^{\frac{\varepsilon}{\varepsilon-1}} \\
& =\left[\left(\lambda_{t}^{s c}\right)^{\varepsilon-1} S_{t}^{\frac{\varepsilon-1}{\varepsilon}} \int_{0}^{1}\left[P_{j t}^{-\varepsilon}\left(\frac{A_{j t}}{A_{t}}\right)^{-\varepsilon \nu}\right]^{\frac{\varepsilon-1}{\varepsilon}} d j\right]^{\frac{\varepsilon}{\varepsilon-1}} \\
& =\left(\lambda_{t}^{s c}\right)^{\varepsilon} S_{t}\left[\int_{0}^{1}\left[P_{j t}^{-\varepsilon}\left(\frac{A_{j t}}{A_{t}}\right)^{-\varepsilon \nu}\right]^{\frac{\varepsilon-1}{\varepsilon}} d j\right]^{\frac{\varepsilon}{\varepsilon-1}} .
\end{aligned}
$$

Solving equation (60) for $\lambda_{t}^{s c}$ yields 


$$
\begin{aligned}
\lambda_{t}^{s c} & =\left[\int_{0}^{1}\left[P_{j t}^{-\varepsilon}\left(\frac{A_{j t}}{A_{t}}\right)^{-\varepsilon \nu}\right]^{\frac{\varepsilon-1}{\varepsilon}} d j\right]^{\frac{1}{1-\varepsilon}} \\
& =\left[\int_{0}^{1} P_{j t}^{1-\varepsilon}\left(\frac{A_{j t}}{A_{t}}\right)^{\nu(1-\varepsilon)} d j\right]^{\frac{1}{1-\varepsilon}} \\
& =P_{t}
\end{aligned}
$$

where $P_{t}$ is defined as the average real industry price level. Substituting equation (61) into equation (58), the demand function can then be written as

$$
\frac{S_{j t}}{S_{t}}=\left(\frac{P_{j t}}{P_{t}}\right)^{-\varepsilon}\left(\frac{A_{j t}}{A_{t}}\right)^{\theta}
$$

where $\theta=-\varepsilon \nu$. This is the demand function stated in equation (5) of the paper.

\section{APPENDIX B: SUMMARY OF THE MODEL}

(for online publication only)

\section{Basic Model}

Using the ratios and growth rates, the equations of the model consisting of equations (29)-(34), (35)-(41), and (42)-(44) can then be written as

$$
\begin{gathered}
\pi_{1}\left(R_{t}^{C I}\right)^{-1}=\Omega_{1 t} \\
(1-\delta) \zeta E_{t} \frac{\left(1+p_{t+1}\right)}{\left(1+i_{t+1}\right)} \Omega_{2 t+1}+\pi_{2}\left(R_{t}^{P X I}\right)^{-1}=\Omega_{2 t} \\
\Omega_{2 t}-(1-\bar{\xi}) \Omega_{1 t}+\bar{\xi} \Omega_{3 t}=0 \\
\zeta E_{t}\left(\frac{1-\mu}{1+i_{t+1}}\right) \Omega_{3 t+1}-\zeta E_{t}\left(\frac{r_{1 t+1}+\mu}{1+i_{t+1}}\right) \Omega_{1 t+1}=\Omega_{3 t} \\
R_{t}^{C I}+(1-\bar{\xi}) R_{t}^{P S I}+\left(\frac{r_{1 t}+\mu}{1+i_{t}}\right) R_{t-1}^{B I}=1
\end{gathered}
$$




$$
\begin{aligned}
& (1-\delta) \frac{\left(1+p_{t}\right)}{\left(1+i_{t}\right)} R_{t-1}^{P X I}+R_{t}^{P S I}=R_{t}^{P X I} \\
& \frac{(1-\mu)}{\left(1+i_{t}\right)} R_{t-1}^{B I}+\bar{\xi} R_{t}^{P S I}=R_{t}^{B I} \\
& \left(\frac{\varepsilon-1}{\varepsilon}\right)+\kappa_{o} \kappa_{1}\left(R_{t}^{A S}\right)^{\kappa_{1}}\left(R_{t}^{A S}-R_{t}^{Y S}\right)=E_{t} \beta_{t+1} \lambda_{1 t+1}^{f} \\
& \kappa_{o}\left(R_{t}^{A S}\right)^{\kappa_{1}}+\lambda_{1 t}^{f}=\lambda_{2 t}^{f} \\
& E_{t} \beta_{t+1} \lambda_{1 t+1}^{f}+\left(\frac{\theta}{\varepsilon}\right)\left(R_{t}^{A S}\right)^{-1} \\
& -\kappa_{o}\left(R_{t}^{A S}\right)^{\kappa_{1}}\left[\kappa_{1}\left(R_{t}^{A S}\right)^{-1}\left(R_{t}^{A S}-R_{t}^{Y S}\right)+1\right]=\lambda_{1 t}^{f} \\
& \alpha \lambda_{2 t}^{f}=L S_{t} \\
& R_{t}^{A S}\left(1+s_{t}\right)=R_{t-1}^{A S}+R_{t}^{Y S}\left(1+s_{t}\right)-1 \\
& y_{t}=\gamma_{t}+\alpha l_{t} \\
& R_{t}^{P S I}=\frac{\left(1+p_{t}\right)\left(1+s_{t}\right)}{\left(1+i_{t}\right)} R_{t-1}^{P S I} \\
& R_{t}^{Y S}=\frac{\left(1+y_{t}\right)}{\left(1+s_{t}\right)} R_{t-1}^{Y S} \\
& L S_{t}=\frac{\left(1+\omega_{t}\right)\left(1+l_{t}\right)}{\left(1+p_{t}\right)\left(1+y_{t}\right)} L S_{t-1}
\end{aligned}
$$

where $\beta_{t+1}=\frac{1}{1+r_{2 t+1}}, \Omega_{1 t}=I_{t} \lambda_{1 t}^{h}, \Omega_{2 t}=\frac{I_{t} \lambda_{2 t}^{h}}{P_{t}}$, and $\Omega_{3 t}=I_{t} \lambda_{3 t}^{h}$. There are thus sixteen equations in sixteen endogenous variables: $R_{t}^{C I}, R_{t}^{P S I}, R_{t}^{P X I}, R_{t}^{B I}, R_{t}^{A S}, R_{t}^{Y S}, L S_{t}, p_{t}, s_{t}, y_{t}, l_{t}, \Omega_{1 t}$, $\Omega_{2 t}, \Omega_{3 t}, \lambda_{1 t}^{f}$, and $\lambda_{2 t}^{f}$.

\section{Reduced Model: Eliminating Labor Input and Productivity Growth}

To eliminate labor input, solve equation (74) for $l_{t}$ to get 


$$
l_{t}=\frac{1}{\alpha}\left(y_{t}-\gamma_{t}\right) .
$$

Substitute equation (78) into equation (77) to get

$$
L S_{t}=\frac{\left(1+\omega_{t}\right)\left(1+\frac{1}{\alpha} y_{t}-\frac{1}{\alpha} \gamma_{t}\right)}{\left(1+p_{t}\right)\left(1+y_{t}\right)} L S_{t-1} .
$$

Now, solve equation (79) for $\gamma_{t}$ to get

$$
\gamma_{t}=\alpha+y_{t}-\alpha \frac{L S_{t}}{L S_{t-1}} \frac{\left(1+p_{t}\right)\left(1+y_{t}\right)}{\left(1+\omega_{t}\right)} .
$$

Lagging equation (80), multiplying the resulting equation by $\rho_{\gamma}$, and subtracting that equation from equation (80) yields

$$
\begin{aligned}
\gamma_{t}-\rho_{\gamma} \gamma_{t-1}= & \alpha\left(1-\rho_{\gamma}\right)+y_{t}-\rho_{\gamma} y_{t-1}-\alpha \frac{L S_{t}}{L S_{t-1}} \frac{\left(1+p_{t}\right)\left(1+y_{t}\right)}{\left(1+\omega_{t}\right)} \\
& +\rho_{\gamma} \alpha \frac{L S_{t-1}}{L S_{t-2}} \frac{\left(1+p_{t-1}\right)\left(1+y_{t-1}\right)}{\left(1+\omega_{t-1}\right)} .
\end{aligned}
$$

But, from equation (50),

$$
\gamma_{t}-\rho_{\gamma} \gamma_{t-1}=\bar{\gamma}\left(1-\rho_{\gamma}\right)+\eta_{t}^{\gamma}
$$

Substituting equation (82) into equation (81) and rearranging terms yield

$$
\begin{aligned}
y_{t}= & (\bar{\gamma}-\alpha)\left(1-\rho_{\gamma}\right)+\rho_{\gamma} y_{t-1}+\alpha \frac{\left(1+p_{t}\right)\left(1+y_{t}\right)}{\left(1+\omega_{t}\right)}\left(\frac{L S_{t}}{L S_{t-1}}\right) \\
& -\alpha \rho_{\gamma} \frac{\left(1+p_{t-1}\right)\left(1+y_{t-1}\right)}{\left(1+\omega_{t-1}\right)}\left(\frac{L S_{t-1}}{L S_{t-2}}\right)+\eta_{t}^{\gamma} .
\end{aligned}
$$

Having eliminated $l_{t}$, the model reduces to fifteen equations in fifteen endogenous variables.

\section{Steady State: Market Equilibrium}

The steady state of the model is

$$
\begin{gathered}
\pi_{1}\left(\bar{R}^{C I}\right)^{-1}=\bar{\Omega}_{1} \\
(1-\delta) \zeta \frac{(1+\bar{p})}{(1+\bar{i})} \bar{\Omega}_{2}+\pi_{2}\left(\bar{R}^{P X I}\right)^{-1}=\bar{\Omega}_{2}
\end{gathered}
$$




$$
\begin{aligned}
& \bar{\Omega}_{2}-(1-\bar{\xi}) \bar{\Omega}_{1}+\bar{\xi}_{3}=0 \\
& \zeta\left(\frac{1-\mu}{1+\bar{i}}\right) \bar{\Omega}_{3}-\zeta\left(\frac{\bar{r}_{1}+\mu}{1+\bar{i}}\right) \bar{\Omega}_{1}=\bar{\Omega}_{3} \\
& \bar{R}^{C I}+(1-\bar{\xi}) \bar{R}^{P S I}+\left(\frac{\bar{r}_{1}+\mu}{1+\bar{i}}\right) \bar{R}^{B I}=1 \\
& (1-\delta) \frac{(1+\bar{p})}{(1+\bar{i})} \bar{R}^{P X I}+\bar{R}^{P S I}=\bar{R}^{P X I} \\
& \frac{(1-\mu)}{(1+\bar{i})} \bar{R}^{B I}+\bar{\xi}^{P S I}=\bar{R}^{B I} \\
& \left(\frac{\varepsilon-1}{\varepsilon}\right)+\kappa_{o} \kappa_{1}\left(\bar{R}^{A S}\right)^{\kappa_{1}}\left(\bar{R}^{A S}-\bar{R}^{Y S}\right)=\overline{\beta \lambda}_{1}^{f} \\
& \kappa_{o}\left(\bar{R}^{A S}\right)^{\kappa_{1}}+\bar{\lambda}_{1}^{f}=\bar{\lambda}_{2}^{f} \\
& \overline{\beta \lambda}_{1}^{f}+\left(\frac{\theta}{\varepsilon}\right)\left(\bar{R}^{A S}\right)^{-1} \\
& -\kappa_{o}\left(\bar{R}^{A S}\right)^{\kappa_{1}}\left[\kappa_{1}\left(\bar{R}^{A S}\right)^{-1}\left(\bar{R}^{A S}-\bar{R}^{Y S}\right)+1\right]=\bar{\lambda}_{1}^{f} \\
& \alpha \bar{\lambda}_{2}^{f}=\overline{L S} \\
& \bar{R}^{A S}(1+\bar{s})=\bar{R}^{A S}+\bar{R}^{Y S}(1+\bar{s})-1 \\
& \bar{p}+\bar{s}=\bar{i} \\
& \bar{y}=\bar{s} \\
& \bar{y}=\frac{\bar{\gamma}}{1-\alpha}+\left(\frac{\alpha}{1-\alpha}\right)(\bar{p}-\bar{\omega})-=0
\end{aligned}
$$

where $\bar{\beta}=\frac{1}{1+\bar{r}_{2}}$. The steady state now consists of fifteen equations in fifteen endogenous variables: $\bar{R}^{C I}, \bar{R}^{P S I}, \bar{R}^{P X I}, \bar{R}^{B I}, \bar{R}^{A S}, \bar{R}^{Y S}, \overline{L S}, \bar{p}, \bar{s}, \bar{y}, \bar{\Omega}_{1}, \bar{\Omega}_{2}, \bar{\Omega}_{3}, \bar{\lambda}^{f}{ }_{1}$ and $\bar{\lambda}_{2}^{f}$. 


\title{
APPENDIX C: DATA DETAILS
}

\author{
(for online publication only)
}

To construct the timeseries of domestic sales, domestic output, domestic inventories, and average price for light trucks, some work is required. The BEA publishes domestic light trucks sales from 1972 onward, but not domestic production nor domestic inventories. From 1985 onward, Ward's Automotive provides detailed data on light truck inventories for the United States. Although this measure includes some foreign light truck inventories, we use this measure as an approximation of domestic inventories. The key assumption behind our approximation is that changes in Ward's inventories reflect mainly changes in domestic inventories, a reasonable conjecture given that light trucks are dominated by U.S. manufacturers.

Because Ward's data reaches back only to 1985, we use a different technique to approximate domestic inventories from 1972 to 1985. We assume that the days' supply figures for light trucks and automobiles are equal over this period. Days' supply is a measure of the number of days vehicles can be sold at the current rate out of the current stock of inventories. This statistic is often used in the industry as a gauge of whether automakers are holding too many or too few vehicles in inventory. Hence, we are assuming that automakers choose to target the same days' supply figures for automobiles and light trucks. Indeed, from 1985 onward, days' supply for automobiles and light trucks has a correlation of 0.69. An advantage to this approach is that automotive days' supply will pick up macroeconomic shocks and allow us to incorporate them into our domestic light truck inventory measure. With light truck domestic sales and our estimate of days' supply, we can back out domestic light truck inventories from 1972 to 1985. Finally, we use the time series of domestic sales and inventories to back out domestic light truck production. ${ }^{24}$

We construct the average price for light trucks using quarterly data on personal consumption expenditures and private investment. ${ }^{25}$ Before 1987, only investment in trucks is published. We approximate the level of light truck investment from 1972 to 1986 by assuming that light truck investment has the same growth rate as total truck investment over this time period. We then divide the sum of the personal consumption expenditures and private investment by unit sales to arrive at an average price. This average price is for all light trucks, but we assume it is a good approximation of domestic light trucks based on the small market share of foreign light trucks. Because we computed average prices for light trucks at the quarterly frequency, we use linear interpolation to construct a monthly series.

\footnotetext{
${ }^{24}$ We checked our inferred measure of domestic light truck production against U.S. light truck assemblies. As expected, the correlation between these two series is a high 0.976. Furthermore, domestic production is typically higher than U.S. assemblies; the average difference between monthly domestic light truck production and U.S. assemblies is more than 44,000 units.

${ }^{25}$ Because government investment in light trucks is small and, for most of the time periods we examine, not published separately from medium and heavy truck investment, we do not include it in our average price calculations.
} 